\title{
A review of the Match technique as applied to AASE-2/EASOE and SOLVE/THESEO 2000
}

\author{
G. A. Morris ${ }^{1,2, *}$, B. R. Bojkov ${ }^{3}$, L. R. Lait ${ }^{3}$, and M. R. Schoeberl ${ }^{3}$ \\ ${ }^{1}$ Dept. of Physics and Astronomy, Rice University, Houston, TX, USA \\ ${ }^{2}$ Goddard Earth Science and Technology Center, University of Maryland Baltimore County, Baltimore, MD, USA \\ ${ }^{3}$ Laboratory for Atmospheres, NASA Goddard Space Flight Center, Greenbelt, MD, USA \\ *now at: Dept. of Physics and Astronomy, Valparaiso University, Valparaiso, IN, USA
}

Received: 4 June 2004 - Published in Atmos. Chem. Phys. Discuss.: 20 August 2004

Revised: 30 May 2005 - Accepted: 13 September 2005 - Published: 28 September 2005

\begin{abstract}
We apply the NASA Goddard Trajectory Model to data from a series of ozonesondes to derive ozone loss rates in the lower stratosphere for the AASE-2/EASOE mission (January-March 1992) and for the SOLVE/THESEO 2000 mission (January-March 2000) in an approach similar to Match. Ozone loss rates are computed by comparing the ozone concentrations provided by ozonesondes launched at the beginning and end of the trajectories connecting the launches. We investigate the sensitivity of the Match results to the various parameters used to reject potential matches in the original Match technique. While these filters effectively eliminate from consideration $80 \%$ of the matched sonde pairs and $>99 \%$ of matched observations in our study, we conclude that only a filter based on potential vorticity changes along the calculated back trajectories seems warranted. Our study also demonstrates that the ozone loss rates estimated in Match can vary by up to a factor of two depending upon the precise trajectory paths calculated for each trajectory. As a result, the statistical uncertainties published with previous Match results might need to be augmented by an additional systematic error. The sensitivity to the trajectory path is particularly pronounced in the month of January, for which the largest ozone loss rate discrepancies between photochemical models and Match are found. For most of the two study periods, our ozone loss rates agree with those previously published. Notable exceptions are found for January 1992 at $475 \mathrm{~K}$ and late February/early March 2000 at $450 \mathrm{~K}$, both periods during which we generally find smaller loss rates than the previous Match studies. Integrated ozone loss rates estimated by Match in both of those years compare well with those found in numerous other studies and in a potential vorticity/potential temperature approach shown previously and in this paper. Finally, we suggest an alternate approach to Match using trajectory mapping. This approach uses infor-
\end{abstract}

Correspondence to: G. A. Morris

(gary.morris@valpo.edu) mation from all matched observations without filtering and uses a two-parameter fit to the data to produce robust ozone loss rate estimates. As compared to loss rates from our version of Match, the trajectory mapping approach produces generally smaller loss rates, frequently not statistically significantly different from zero, calling into question the efficacy of the Match approach.

\section{Introduction}

Significant progress has been made in understanding the photochemistry of the polar stratosphere since the ozone hole began to appear in the 1980's (Solomon, 1999). An important demonstration of our understanding, however, is our ability to reconcile the prediction of photochemical models with observed ozone loss. In the Arctic winter stratosphere this problem is especially challenging because the Arctic vortex is less well isolated than the Antarctic vortex and because in the beginning of winter, ozone amounts inside the vortex are higher than outside for altitudes below about $25 \mathrm{~km}$ (see AASE special issue of the Journal of Geophysical Research, 97, D8). Thus separating changes in Arctic ozone due to dynamic processes (such as mixing) from changes due chemical loss is a challenge.

One approach to untangling the roles of dynamic and chemical processes in observed ozone change is to use measurements of a conservative trace gas species made at the same times as the measurements of ozone. Each ozone observation is tagged with a simultaneous measurement of the trace gas species. Subsequent ozone measurements are then compared to prior ozone measurements that were tagged with similar values of the trace gas. Chemical ozone loss can be inferred from shifts in the conservative trace gas - ozone correlation. For example, Schoeberl et al. (1991) used simultaneous $\mathrm{N}_{2} \mathrm{O}$ and $\mathrm{O}_{3}$ measurements to estimate Arctic ozone loss during the late winter as part of the Airborne Arctic

(C) 2005 Author(s). This work is licensed under a Creative Commons License. 
Stratospheric Expedition (1989). Sinnhuber et al. (2000) use a passive ozone tracer in their chemical transport model and estimate ozone loss by comparing ozone observations with the value of the passive ozone tracer from the model. Tilmes et al. $(2003,2004)$ calculate ozone loss in the Arctic vortex for winters from 1991-2003 using HALOE and ILAS profiles.

Plumb et al. (2000) show that even in the absence of chemical processing, conservative trace gas - ozone correlations will evolve due to continuous dynamic mixing processes. As a result, such correlations should not be applied over extended periods. Failure to account for changes in the correlative relationships can lead to incorrect estimations of vortex ozone loss and denitrification. To reduce the probability of mistakenly attributing ozone changes to chemical rather than dynamic (mixing) processes, Richard et al. (2001) compute the ozone loss during the SOLVE (Sage III Ozone Loss and Validation Experiment) 1999-2000 winter period using ozone and two conservative tracers.

Unfortunately most ozone measurements are made without the simultaneous measurement of long-lived tracer fields (e.g. lidar measurements, some satellite measurements, and ozonesondes) let alone the two additional trace gas fields required in the approach of Richard et al. (2001). Thus we need to be able to estimate ozone loss without the use of long lived tracers.

Pseudo-tracers have also been used to separate dynamics from chemistry in estimating ozone loss. For example, Manney et al. (1994) and Lait et al. (2002) use potential vorticity (PV) as a pseudo-tracer to estimate ozone loss, but their approaches require high quality $\mathrm{PV}$ computations, and $\mathrm{PV}$ is not strictly conserved under diabatic processes.

Another approach to this problem, and the focus of this paper, involves the combination of ozonesonde observations with a simulation of atmospheric dynamics as calculated by a trajectory model. This technique, called Match, has been applied to data from 1992-2003 in the Arctic (von der Gathen et al., 1995; Rex et al., 1997, 1998, 1999, 2002; Schultz et al., 2000, 2001) and in 2003 in the Antarctic. By tracking an air mass measured by one ozonesonde through space and time until it arrives at the location of a second measurement by another ozonesonde, we can infer chemical ozone loss from the observed change in ozone between the two measurements. Published ozone loss rates calculated using Match for cold Arctic Januaries are generally about $30 \%$ larger than can be explained by our current understanding of polar stratospheric chemistry, with one to two individual data points in January 1992 that exceed model values by more than a factor of two (Becker et al., 1998).

Schoeberl et al. (2002) introduce a variant on the Match technique that uses many sources of data (sonde, satellite and aircraft) to initialize air parcel trajectories. By comparing new observations with the ozone values associated with the older, advected air parcels, chemical ozone loss again can be inferred.
In this paper we summarize the original Match technique, delineate the differences between the original technique and our version of Match, examine the sensitivity of our version of Match to a variety of filters that have been applied to Match data, and describe an alternate approach to Match based upon trajectory mapping (Morris et al., 1995). We confine our data analysis to the two years 1992 and 2000, corresponding to the AASE-2/EASOE mission and to the SOLVE/THESEO 2000 mission respectively.

\section{Methodology}

We begin with a brief discussion of the characteristics of the ozonesonde data that form the basis of Match. We then review the original Match technique as employed in the series of Match papers (e.g., Rex et al., 1998). Since our first research task is to reproduce the results achieved by Rex and his collaborators for these two missions, we discuss the precise method we used in our version of Match, highlighting the differences with the original Match technique. Next we motivate and introduce a new version of Match using trajectory mapping that we believe yields more realistic estimates of the uncertainties associated with the Match technique. For comparison, we also provide results from the well-established pseudo-tracer approach using PV and potential temperature (the PV/Theta approach, see Schoeberl and Lait, 1992).

\subsection{Ozonesonde data and filtering}

The electrochemical concentration cell (ECC) type (Komhyr, 1969, 1986) and Brewer-Mast ozonesondes are a simply designed, lightweight, and inexpensive balloon-born instruments used for measuring the vertical distribution of atmospheric ozone to an altitude of up to $40 \mathrm{~km}$. Numerous intercomparisons with other ozone measuring instruments (Kerr et al., 1994; Komhyr et al., 1995) have demonstrated that ozonesondes are generally accurate. During the STOIC 1989 campaign (Komhyr et al., 1995) the ECC sonde precision, when compared to ground-based LIDARs, microwave ozone instruments, and ozone photometers, was determined to be $\pm 5 \%$ between the tropopause and $10 \mathrm{hPa}(\sim 32 \mathrm{~km})$ in the stratosphere (the uncertainty in the troposphere was found to be $\pm 6 \%$ near the ground and $-7 \%$ to $+17 \%$ in the upper troposphere, and in the stratosphere was found to be $-14 \%$ to $+6 \%$ at $4 \mathrm{hPa}$ or $38 \mathrm{~km}$ ). The overall error in the soundings are thought to originate from four different sources: the background current of the electrolytic cells, the variations in pump efficiency with decreasing pressure, the accuracy of the measurement of the air temperature in the cathode chamber, and the cell's response time to changing ozone concentrations.

Over 700 ozonesondes were launched during the AASE2/EASOE (January 1992-March 1992) and over 700 
more were launched during the SOLVE/THESEO 2000 (November 1999-March 2000) polar campaigns. Soundings from the 26 (AASE2/EASOE, not shown) and the 32 (SOLVE/THESEO 2000) stations (depicted in Fig. 1), have been homogenized using multiple quality control criteria and filters described below. All ozonesonde data were obtained from the World Meteorological Organization's (WMO's) World Ozone and Ultraviolet Data Centre (WOUDC, http: //www.msc-smc.ec.gc.ca/woudc/).

The first sonde data filter is similar to the approach employed by Bojkov and Bojkov (1997). The filter ensures that each record from an ozonesonde sounding includes a pressure and a temperature measurement, that the altitude gap between ozone measurement is not larger than $500 \mathrm{~m}(\sim 90 \mathrm{~s}$ data gap), and that the sounding reaches an altitude with a pressure of $\sim 20 \mathrm{hPa}(23-25 \mathrm{~km})$. In addition, this initial filtering process also checks for and removes telemetry and ozone "spikes," and flags ozone partial pressure measurements under $1 \mathrm{mPa}$.

The second sonde data filter involves a review of the ozonesonde box temperature data. Since the ozone amount is linearly proportional to the box temperature (Komhyr and Harris, 1971), errors in the box temperature can result in errors in the ozone measurement. A $3 \mathrm{~K}$ error in the measured box temperature translates into a $1 \%$ error in the sampled ozone measurement. In practice, about $2 \%$ of the sondes show unusual behavior in the recorded box temperature data and are eliminated.

From the initial set of 3677 possible sonde-to-sonde matches in AASE2/EASOE on the $475 \mathrm{~K}$ surface and 3423 possible sonde-to-sonde matches in SOLVE/THESEO 2000 on the $450 \mathrm{~K}$ surface, 3071 and 2813 were left, respectively, after applying these two filters exclusively. While these two filters eliminate $15-20 \%$ of the matches, they do not eliminate all problems with the sonde data.

For the original Match technique, the elimination of individual ozonesondes is performed by the Finnish Meteorological Institute in Sodankyla and Alfred Wegener Institute (AWI) in Potstdam. In practice $\sim 10 \%$ of the data are eliminated by these filters in the original Match technique (M. Rex, personal communication, 2004).

\subsection{The original Match technique}

Match campaigns since 1994 involve a coordinated launch of ozonesondes based upon predictions derived from running a trajectory model that uses forecast winds from the European Centre for Medium-range Weather Forecasts (ECMWF). The AASE-2/EASOE campaign in 1992 did not coordinate the launch of ozonesondes for Match. As a result, the procedure for Match in 1992 begins with trajectories calculated in the analysis mode (described below).

In Match, each ozonesonde launch triggers the initialization of air parcels geographically coincident with the sonde location in the isentropoic trajectory model (Peterson and

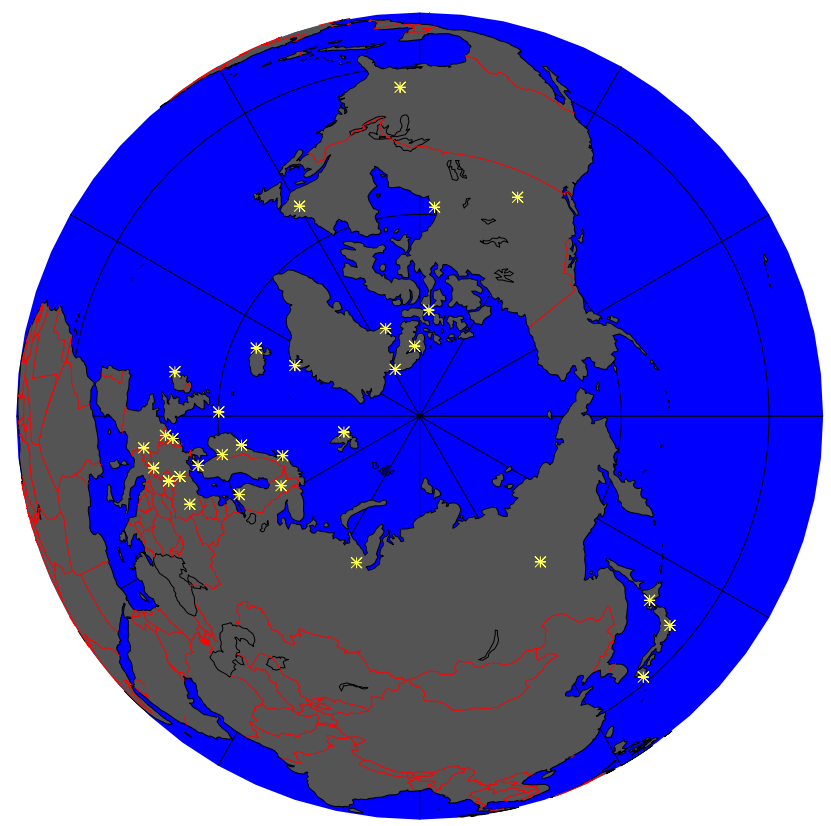

Fig. 1. The map indicates the 32 stations from which ozonesonde data are included in our version of Match for the analysis of data from SOLVE/THESEO 2000.

Uccellini, 1979) along the sonde profile. In forecast mode, isentropic trajectories are run using ECMWF forecast wind fields $\left(2.5^{\circ} \times 2.5^{\circ} \times 6 \mathrm{~h}\right)($ Rex et al., 1999). A diabatic correction to the isentropic trajectories is applied using Lacis and Hansen (1974) for short wave heating and Dickinson (1973) for infrared cooling. When the forecast trajectories closely approach (within $350 \mathrm{~km}$ ) another ozonesonde launch facility, a second, matching ozonesonde is launched (Rex et al., 1999). This coordinated approach to ozonesonde launches improves the prospect of a match occurring.

After the launch of the second ozonesonde, a new set of trajectories is calculated, this time with the trajectory model running in an analysis mode, in other words, using as input the analyzed wind fields from ECMWF $\left(1.5^{\circ} \times 1.5^{\circ} \times 6 \mathrm{~h}\right)$ (Rex et al., 1998). The trajectories are integrated forward in time in a diabatic mode with heating rates derived from the Universities' Global Atmospheric Modeling Program (UGAMP) General Circulation Model (GCM) as established by Geleyn and Hollingsworth (1979) for AASE-2/EASOE (Rex et al., 1998) and from radiative transfer scheme of the SLIMCAT 3-D chemical transport model (Chipperfield, 1999) for SOLVE/THESEO 2000 (Rex et al., 2002). (We note that for 1992, the ECMWF winds are output on $19 \mathrm{lev}$ els from $1000 \mathrm{hPa}$ to $10 \mathrm{hPa}$, while in 2000, ECMWF winds are output on 60 levels to $0.1 \mathrm{hPa}$. Although we have not conducted an appropriate sensitivity study, such differences in the vertical resolution of the ECMWF winds might have an impact on the Match results.) 
The analysis trajectories are limited to 10 days duration and help in the determination of whether or not an actual match occurred. In practice $\sim 80 \%$ of forecast matches result in confirmed matches (M. Rex, personal communication, 2004).

Several quality control measures insure the integrity of each match. Ozone profiles from the second ozonesonde are interpolated to the altitudes at which the matches occur. Interpolations are not performed, however, onto surfaces that lie within vertical gaps in the ozonesonde profile that exceed $500 \mathrm{~m}$ (Rex et al., 1998, 1999). Given typical ascent rates, this distance implies a temporal gap of approximately $90 \mathrm{~s}$ in the ozone profile. Station-to-station and year-to-year differences in the time averaging of ozonesonde profiles that appear in the WMO data files could yield inconsistent results from the application of this criterion.

As the ozonesonde ascends, its latitude and longitude coordinates vary due to transport by the local winds. Separate instrumentation on the same balloon payload (for some ozonesondes) records the winds. This wind data permits the computation of latitude and longitude of the ozonesonde as a function of potential temperature surface for the purposes of initializing each air parcel within the trajectory model. For those sondes that do not record local winds, the winds are interpolated from the 3-D grid of the analyzed wind fields from ECMWF to the ozonesonde profile.

To track each air parcel along the measured profile, a tight cluster of 7 parcels is initialized in the trajectory model on each potential temperature (Theta) surface with a valid ozone measurement: 5 of these parcels are on the Theta surface of interest; one is $5 \mathrm{~K}$ in Theta directly above and one $5 \mathrm{~K}$ directly below. The center of the cluster of 5 on the same Theta surface is at the ozonesonde location. The other 4 in that cluster of 5 are located $100 \mathrm{~km}$ away, one each north, south, east, and west (Rex et al., 1999). The Match study for 1991/1992 was the exception in that this cluster approach was not employed. In all cases, Match trajectories are limited to 10 days duration.

In determining a valid match, only the central parcel in the cluster of 7 is used. If the central parcel lies within the specified Match radius of the location of the second ozonesonde observation, the corresponding ozone observations are said to have been made within the same air mass and a match has occurred. In von der Gathen (1995) the Match radius used for AASE-2/EASOE is $500 \mathrm{~km}$. In Rex et al. (1998), the Match radius used for AASE-2/EASOE is $475 \mathrm{~km}$ (1992) while in Rex et al. (2002), the Match radius is $400 \mathrm{~km}$ (2000). In each case, Rex found the Match radius that achieved a minimum in statistical uncertainty of the ozone loss rate calculation. In other words, if the Match radius is decreased, then fewer matches are found, increasing the statistical uncertainty. Likewise, if the Match radius is increased, more matches occur, but the quality of the matches deteriorates, thereby increasing the statistical uncertainty.
Rex et al. (2002) are able to use a tighter Match radius for SOLVE/THESEO 2000 since launches in 2000 are coordinated using Match forecast trajectories, unlike launches in 1992 for AASE-2/EASOE. Near the vortex boundary, the shape of this Match region is altered from a circle (used for AASE-2/EASOE) to an oval (used in all later Match studies including SOLVE/THESEO 2000) with a major axis of $500 \mathrm{~km}$ parallel to lines of constant PV and a minor axis of $300 \mathrm{~km}$ in the perpendicular direction (Rex et al., 1999). Again, the changes were implemented in the original Match technique in an attempt to minimize the statistical uncertainty associated with the Match results.

The 6 other parcels in each cluster are used to diagnose the validity of the corresponding central trajectory and to filter out air masses that are more likely to have been influenced by mixing processes. Clusters of parcels that remain spatially close together are more likely to describe actual air parcel trajectories. At the time of the match (i.e., the measurement made by the second ozonesonde), the distance from the central parcel to each of the other 6 parcels in the cluster is calculated. If the maximum such distance exceeds $1200 \mathrm{~km}$ for the 5 parcels that began on the same potential temperature surface or $1300 \mathrm{~km}$ for the 2 parcels that began $5 \mathrm{~K}$ above or below, then the match is discarded.

Ozonesonde profiles are also filtered on the vertical gradient in ozone concentrations. For Match during AASE2/EASOE, ozone is allowed to vary by $15 \%$ over the altitude range $2 \mathrm{~K}$ above to $2 \mathrm{~K}$ below the potential temperature surface of the match and $25 \%$ over the altitude range of $5 \mathrm{~K}$ above to $5 \mathrm{~K}$ below the surface of the match (Rex et al. 1998). For Match during SOLVE/THESEO 2000, these restrictions are $20 \%$ and $30 \%$, respectively (Rex et al., 1999). Such restrictions serve two purposes. First, ozonesonde profiles within the Arctic polar vortex often contain sharp gradients due to imbedded filaments of extra-vortex air. Such filaments do not characterize the vortex air mass and, therefore, can complicate the interpretation of the Match results. Second, by examining only those parts of the profile with small vertical gradients in ozone, uncertainties in the diabatic portion of the trajectory calculation that might bias ozone loss rate calculations are reduced. This filter, however, has the potential to eliminate valid ozonesonde data that should be considered in calculating mean ozone loss rates.

Air parcel trajectories that exhibit significant deviations in PV may be less reliable. Therefore, the potential vorticity as calculated along the air parcel trajectory is not allowed to vary by more than $40 \%$ between its maximum and minimum values for AASE-2/EASOE (Rex et al., 1998) and 25\% for SOLVE/THESEO 2000 (Rex et al., 2002). ECMWF analyses switched from a 3-D to a 4-D assimilation process from the 1992 data to the 2000 data, greatly reducing the noise in the PV fields. The $\triangle \mathrm{PV}$ limits are suggested by Rex et al. (1999) at the point where an increase in the scatter of the matched ozonesonde observations is observed. As with the case of the Match radius, the change in the $\Delta \mathrm{PV}$ criterion 
is related to the fact that ozonesonde launches were not coordinated in 1992 for AASE-2/EASOE, reducing the number of available matches. For later campaigns during which the launches are coordinated, more restrictive criteria could be enforced while still resulting in a sufficient number of matches from which to calculate ozone loss rates.

Only matches that occur within the polar vortex or near the edge of the vortex are included in the original Match studies. Rex et al. (1998) use a derived quantity that they call "normalized PV" to locate the vortex edge. This quantity is based upon the scaled PV of Dunkerton and Delisi (1986) and is defined so that the normalized PV and Ertel's PV have the same values at the $475 \mathrm{~K}$ isentropic surface. Rex et al. (1998) use a vortex boundary of 36 normalized PV units (1 PVU $=10^{6} \mathrm{~K} \mathrm{~m}^{2} / \mathrm{s} / \mathrm{kg}$ ), so that the Match data include air parcels at the vortex edge. As a result, the vortex size is 10$15 \%$ larger than the area poleward of the PV contour at the maximum PV gradient.

Finally, each tracked air parcel is only permitted a single match with each other sonde on a given day, although it may match multiple sondes on the same day.

To compute the ozone loss rate (ppbv per sunlit hour), the total amount of sunlight along the back trajectory is calculated. To determine the number of hours of solar illumination, a careful calculation is performed to determine if the center of the solar disk is visible at the precise location of the air parcel. This calculation includes atmospheric refraction effects and the non-spherical shape of the Earth. The time over which the air parcel can see the center of the solar disk is integrated to compute hours of solar illumination. The ozone loss rate can be determined by dividing the difference between the ozone measurements of the new ozonesonde and that of the original ozonesonde by the total number of hours of solar illumination.

A more robust approach than calculating a loss rate for each match is to calculate the loss rate for an ensemble of matches. In practice, matches are accumulated over a 14-day (1992) or a 20-day (2000) period. A regression is performed of ozone change on hours of solar illumination to produce a line-of-best-fit. The slope of that line is the ozone loss rate. The ozone loss rates are computed this way once per week. Uncertainty in the calculated ozone loss rates is computed using the standard statistical methods. The regression line is forced to pass through the origin since air parcels that have not been exposed to sunlight should not experience chemical ozone loss. To justify this procedure, Rex et al. (1998) and Rex et al. (2003) performed multi-variable regression on sunlit hours and dark hours using Match data and observed little to no ozone change during the dark hours.

Finally, Match results are presented on potential temperature (Theta) surfaces. All matches within $\pm 10 \mathrm{~K}$ are included with results shown "on" a given theta surface.

\subsection{Our version of the Match technique}

In our attempts to reproduce the results of Rex et al. (1998, 2002), we have used a very similar approach to that described above with the following exceptions. We initialize parcels at every altitude for which the ozonesonde data files report a measurement. Each observation is initialized as a cluster of parcels, one each $50 \mathrm{~km}$ north, south, east and west of a central parcel at the location of the ozonesonde measurement, but only the center one is used to define a match. We include matches within the polar vortex as defined using modified potential vorticity (MPV) (Lait, 1994) and a maximum gradient definition of the vortex boundary (Nash et al., 1996). To approximate the weak definition of the vortex boundary used in the original Match technique, we use a MPV criterion of the weakest edge (defined by the nearest to the vortex boundary of the maximum of the second derivative of MPV). We compute ozone loss rates daily so that it is easy to identify days for which something unusual occurs.

To determine the number of hours of solar illumination, the parcel location and local time at each point along the trajectory is used to compute the solar zenith angle (SZA). The parcel is considered to be illuminated if the SZA is less than $95^{\circ}$, a value recommended by M. Rex (personal communication, 2003). At $20 \mathrm{~km}$, a height very near that of all of the potential temperature surfaces considered in this study, this SZA corresponds to the Sun being nearly on the horizon. (Calculations indicate that the Sun on the horizon corresponds to angles of $94^{\circ}$ to $95^{\circ}$ for altitudes between 15 and $25 \mathrm{~km}$.) We note that although the photochemistry may initiate at a SZA slightly greater than $95^{\circ}$, the uncertainties in the trajectories themselves will produce larger errors, making consideration of the uncertainty in the precise SZA less important.

Our version of Match restricts air parcels from each sonde to match any other given sonde exactly once. Since we do not initialize extra parcels $5 \mathrm{~K}$ above and below each observation, we do not apply the 1300-km parcel spreading filter (see text above) of Rex et al. (1999).

To provide an estimate of the robustness of the results, we introduce a random component to select subsets of matches with which to compute ozone loss rates. This random selection process is done in an iterative way so that a wide range of possible outcomes are represented. To compute uncertainties, we examine both the scatter of these outcomes as well as a bootstrap approach (Efron, 1982) applied to any one particular outcome. In the bootstrap approach, a new random subset of size equal to the size of the original data set is generated with duplicates permitted. Linear regression is performed on the subset; the process repeated; and the slopes accumulated. The uncertainty of the ozone loss rate can be estimated by the standard deviation of the set of slopes. We iterate for a minimum of 200 subsets and until the change in the standard deviation from one iteration to the next is less 
than $0.001 \%$ of the previous value or until we have iterated 20000 times, whichever occurs first.

As is the case with the analysis in the original Match studies, we constrain our linear regression to pass through zero change in ozone with zero sunlit hours. The justification for this approach is provided by the multivariable regression analysis that indicates no loss in the dark (see Sect. 3 below).

Finally, we employ wind fields $\left(3.75^{\circ} \times 2.5^{\circ} \times 24 \mathrm{~h}\right)$ from the United Kingdom Meteorological Office (UKMO) (Swinbank and O'Niell, 1994) with heating rates calculated as in Rosenfield et al. (1994) and use trajectories of up to 14 days duration as calculated by the Goddard Trajectory Model (Schoeberl and Sparling, 1995). Lucic et al. (1999) note that the UGAMP derived heating rates used by Rex et al. (1998) result in about $0.2 \mathrm{~K} /$ day more descent than those computed by Rosenfield et al. (1994) for the 1991/1992 winter season, a consideration to keep in mind when comparing our results with those from the original Match technique. Also worth considering is the impact of the reduced time resolution of our wind fields compared to those used in the original Match studies. Waugh and Plumb (1994) noted that Lagrangian estimates of atmospheric dynamics depend strongly on the time resolution of the meteorological fields.

\subsection{Potential vorticity/potential temperature approach}

As a check on our results, we include the calculation of integrated loss rates over the winters of 1992 and 2000 using the PV/Theta approach. Built upon the ideas of McIntyre (1980), advanced by Schoeberl et al. (1989), and finally formalized by Schoeberl and Lait (1992), the PV/Theta approach takes advantage of the quasi-conserved nature of both PV and Theta and has been applied in numerous studies to problems involving sparse data sets (Lait et al., 2002; Randall et al., 2002; Strahan, 1999a; Strahan et al., 1999b; Lucic, et al., 1999; Manney et al., 1999; Plumb, et al., 1995, Redaelli, et al., 1994; Salawitch, et al., 1993; Lait, et al., 1990; Douglass et al., 1990; Salawitch, et al., 1990). Ozone observations are located in a PV/Theta coordinate space using values of PV and Theta which have been corrected for diabatic effects by means of trajectory calculations (Lait et al., 2002). For each point in a regularly-spaced grid in the $\mathrm{PV} /$ Theta coordinate space, a weighted linear least-squares fit is applied to the ozone data near that gridpoint to obtain a chemical loss rate.

With regards to this study, we use all available ozonesondes north of $60^{\circ}$ latitude associated with PV values among the highest $10 \%$ of all PV values on a given Theta surface on a given day to represent the core of the polar vortex. These sonde data were used to construct the PV/Theta - ozone relationships.

Trajectory calculations are used to determine descent and to identify parcels that crossed the vortex boundary. Those parcels for which trajectory calculations indicated a variation in the Modified Ertel's Potential Vorticity (MPV) of more than $12.5 \%$ are eliminated from consideration. If the MPV criterion is set to too high of a value, parcels would be included which crossed the vortex boundary. In that case, the effects of mixing would contribute to observed ozone change in addition to changes resulting from diabatic descent and chemical loss. Mixing effects manifest themselves through greater scatter in the ozone values about a point in PV-theta space. If the criterion is set too low, then too few parcels will be chosen, resulting in less than desirable statistics. The $12.5 \%$ threshold appears to provide the right balance between these two competing effects.

The trajectories are calculated to the date at the middle of the analysis range. For example, when studying data from 1 January through 29 February 1992, trajectories are run either forward or backward in time, as appropriate, to 30 January. As a result, comparing loss rates at a particular Theta surface is most accurate for 30 January. PV/Theta loss rates will be somewhat displaced vertically as compared to Match results for earlier or later days.

\section{Diagnostics and sensitivity studies}

In this section, we demonstrate the equivalence of our version of Match and the original version. We also explore the sensitivity of our version of Match to the Match filters applied by Rex et al. $(1998,2002)$ and described above. As we show below, most of the filters seem not to impact the results.

First, we attempt to reproduce Fig. 6 from Rex et al. (1998). In that figure, the authors show the linear relationship between change in ozone and the hours of sunlight illumination as computed from data for the period of the largest ozone loss rates, 4 January-9 February 1992, during the AASE-2/EASOE campaign. We therefore bin all of the Match data from this period by the number of hours of solar illumination with bins $20 \mathrm{~h}$ wide, plotting one data point for each $10 \mathrm{~h}$ of sunlight illumination, as did the original authors.

Figure 2 shows both the original data from Rex et al. (1998) (red) and data from our version of Match (blue). Note that we extend the data beyond the limit of $65 \mathrm{~h}$ of sunlight illumination that appears in the original figure to near $85 \mathrm{~h}$ of sunlight. Error bars for both sets of data represent one standard deviation. Our data points represent the average of both the ozone change and the number of hours of sunlight illumination within each bin and are plotted with an associated error bar for both quantities based on the variance within each bin.

Based on Fig. 2, the case can be made that the ozone change is linearly related to the amount of sunlight to which the air parcel is exposed, as is expected from our current understanding of polar winter photochemistry (Solomon, 1999). Furthermore, the agreement between the results of Rex et al. (1998) and our data indicates that we have done a reasonably good job of reproducing Match. 


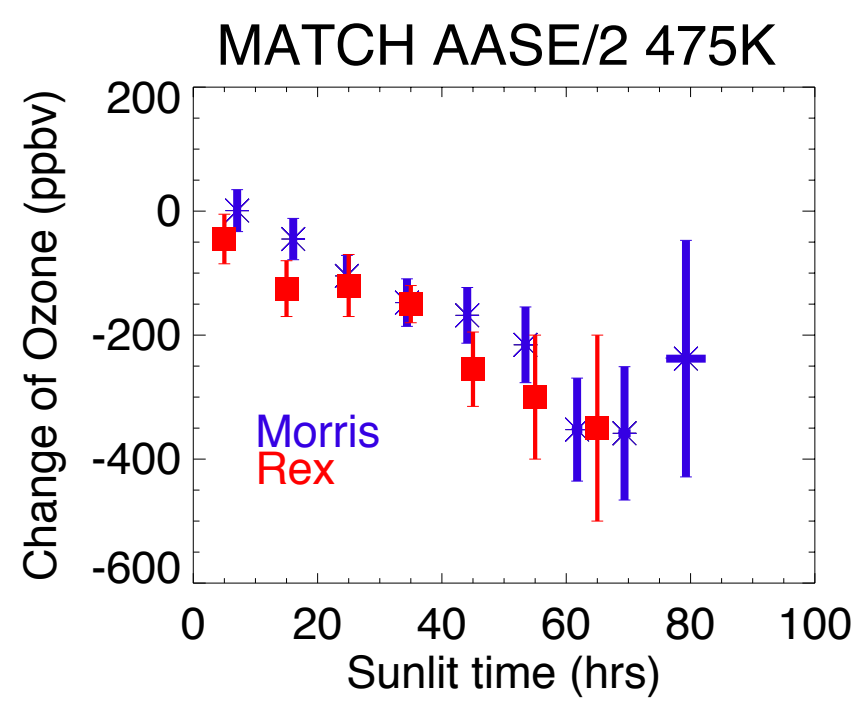

Fig. 2. Our attempt to reproduce Fig. 6 from Rex et al. (1998) showing the relationship between the average change in ozone and hours of sunlight illumination. The original data from Rex et al. (1998) are plotted in red while our data are plotted in blue. Error bars for both data sets are one standard deviation. Note that we extend the computation beyond the $65 \mathrm{~h}$ of sunlight that appeared in the original figure to $\sim 85 \mathrm{~h}$. We also show the standard deviation of the amount of solar illumination in each bin using horizontal error bars.

To further validate our model, we perform a bivariate regression of ozone change on sunlit and dark hours along the calculated trajectories on the $475 \mathrm{~K}$ Theta surface using our Match data from 1 January-9 February 1992, as done in Rex et al. (1998). We find the change in ozone per hour of sunlight is $-3.25 \mathrm{ppbv}$ while the change in ozone per hour of darkness is $+0.01 \mathrm{ppbv}$. Rex et al. (1998) found the change in ozone per hour of sunlight to be $-7.0 \pm 1.5 \mathrm{ppbv}$ while the change in ozone per hour of darkness to be $+0.5 \pm 0.4 \mathrm{ppbv}$.

We also computed the average ozone change for the subset of our matches which received no sunlight along the calculated trajectories. For this subset, we found an average change in ozone of $10 \pm 160 \mathrm{ppbv}$, suggesting that we have not inadvertently introduced a bias in our results.

Next, we examine the sensitivity of the ozone loss rate results to the following parameters: (1) PV difference along the back trajectory; (2) spreading of the cluster of parcels initialized for each ozonesonde measurement; (3) the duration of trajectories between matches; (4) the PV value used to define the vortex boundary; (5) the precise SZA at which the terminator is defined in the calculation of the number of hours of solar illumination; (6) the combined use of all the filters in the original Match technique, and (7) the choice of meteorological field. The filters employed in the original Match technique were selected to minimize the root-mean-square errors (personal communication, M. Rex, 2003). Here, we attempt to evaluate the necessity of these filters and the choice of meteorological data through these sensitivity studies.

\section{MATCH Senstitivity}

\section{MPV Difference Along Trajectory}

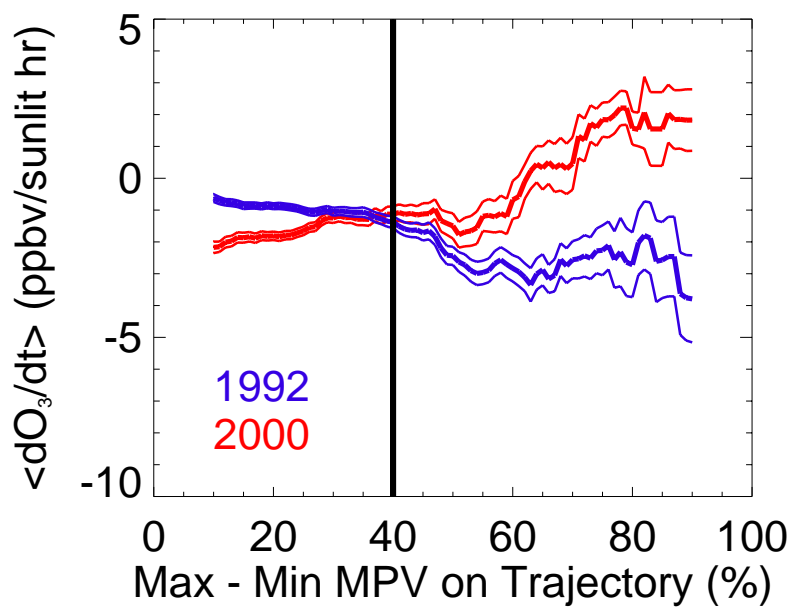

Fig. 3. The sensitivity of the ozone loss rate on the maximum minus minimum PV difference along the back trajectory (see text) is explored for AASE-2/EASOE (blue) and SOLVE/THESEO 2000 (red). The thick lines represent the mean values while the thin lines represent the means plus and minus one standard deviation.

\subsection{PV differences}

To examine the impact on the ozone loss rate of the PV difference along the back trajectories, we bin all the data from 1992 and 2000 by the ozone loss rate and plot the mean loss rate and standard deviation for each year in Fig. 3. In the figure, data from AASE-2/EASOE appears blue while data from SOLVE/THESEO 2000 appears red. The thick lines represent the mean quantities while the thin lines represent the mean plus and minus one standard deviation. To compute these error bars, we employ the bootstrap technique (see Sect. 2.3 above). The vertical, solid black line at $40 \%$ represents the filter value employed by Rex et al. (1998).

Figure 3 shows that the average loss rates are well behaved for PV differences of less than $40 \%$. In other words, the standard deviation of the mean ozone loss rate remains relatively constant over this domain. Beyond 50\% PV differences, it is clear that neither the ozone loss rate nor the standard deviation remain constant or predictable. Therefore, the cutoff value of $40 \%$ used by Rex et al. (1998) appears to be a valid and useful parameter by which to filter out less reliable Match data.

Grooß and Müller (2003) performed a sensitivity analysis of the original Match technique to the PV filtering criterion using the Chemical Lagrangian Model of the Stratosphere (CLaMS). They applied a cut-off value for PV of $25 \%$ as in Rex et al. (1999) and as applied to all Match campaigns after AASE-2/EASOE in 1992. After applying 


\section{MATCH Senstitivity}

\section{Parcel Spreading Along Trajectory}

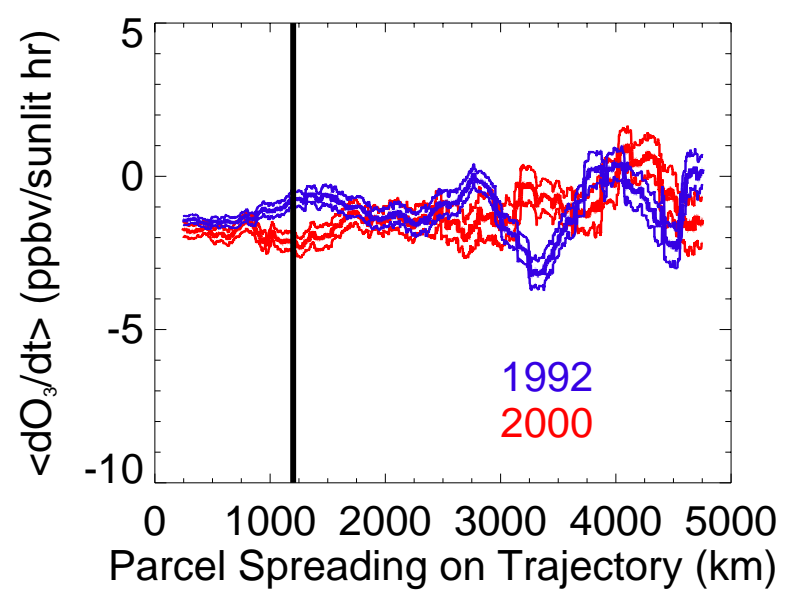

Fig. 4. Same as for Fig. 3 except that this figure explores the sensitivity of the loss rates to the maximum distance of parcel spreading (see text).

the PV filter, they observe that the ozone loss rate bias that results from the original Match technique as compared to CLaMS changes from $+2.40 \pm 0.07 \mathrm{ppbv} / \mathrm{sunlit}$ hour to $-0.41 \pm 0.08 \mathrm{ppbv} / \mathrm{sunlit}$ hour, a significant effect. We note that in their study, the Match radius is $300 \mathrm{~km}$ and the trajectory length is 4 days, parameters different from the original Match technique and our version of Match. Nevertheless, our results concur with those of Grooß and Müller (2003) and indicate that the PV filter criterion is an important one for the successful application of Match. From our results a $\Delta \mathrm{PV}$ cut-off of 40\% may be optimal both in 1992 and in 2000, so unlike Rex et al. (2002), we do not recommend changing the cutoff to 25\% for the SOLVE/THESEO 2000 study period (although to be consistent and for ease of comparison with the results of Rex et al. (1999, 2002), we do so in the studies presented below).

\subsection{Cluster spreading}

Next, we examine the sensitivity of the results to the spreading of the cluster of trajectories that was initialized with each ozonesonde observation. Rex (1993) established a criterion to filter Match data for which the trajectory of at least one member of the cluster led to a separation of more than $1200 \mathrm{~km}$ from the central parcel at the time of the Match. Figure 4 shows the average ozone loss rate as a function of the maximum spreading of each cluster of trajectories. Again, AASE-2/EASOE is shown in blue while SOLVE/THESEO 2000 is shown in red, and the thick lines represent the mean values while the thin lines represent the means plus and minus one standard deviation as computed
MATCH Senstitivity Trajectory Duration

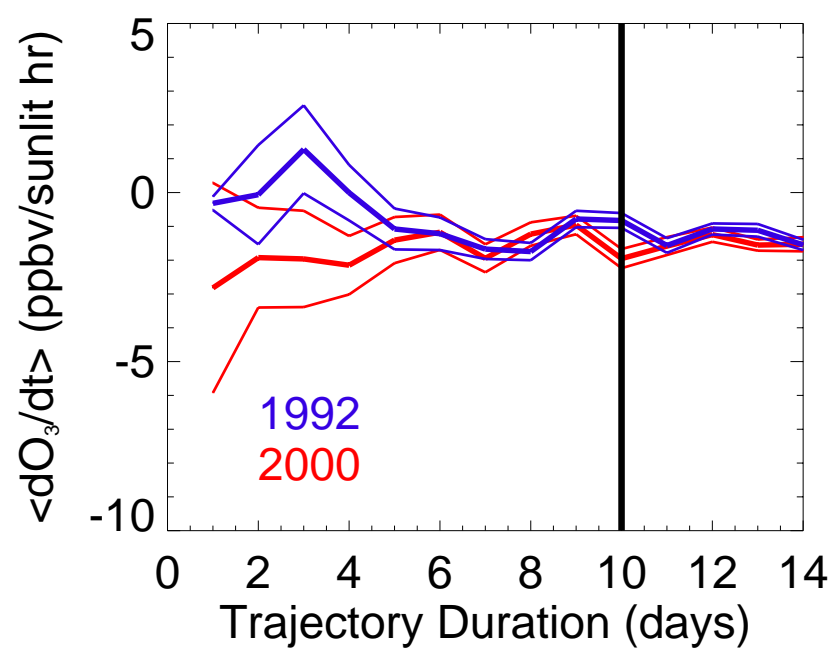

Fig. 5. Same as for Fig. 3 except that this figure explores the sensitivity of the loss rates on the duration of the trajectories in the match (see text).

using the bootstrap technique. The vertical, solid black line at $1200 \mathrm{~km}$ represents the filter value used in Rex (1993).

This quantity is much better behaved than the PV differences seen in Fig. 3. In fact, it is difficult to assign an appropriate distance at which a transition occurs to justify establishing a cut-off value for parcel spreading on which to filter matches. Based on Fig. 4, it appears that the cut-off for parcel spreading need be no more restrictive than $2500 \mathrm{~km}$ and in fact may be entirely unnecessary. We also note that the cluster spreading criterion in the original Match technique was based on parcels that started out $100 \mathrm{~km}$ from the central parcel, twice as far away as in our version of Match. The results of Fig. 4, therefore, should be viewed as an upper limit for the impact of this filter on the original Match technique.

Our results differ from those achieved by Grooß and Müller (2003). They found that by applying the cluster spreading filter criterion of Rex et al. (1998), the bias in the ozone loss rate calculated in Match compared to CLaMS changes from $+2.40 \pm 0.07 \mathrm{ppbv} / \mathrm{sunlit}$ hour to $-0.23 \pm 0.07 \mathrm{ppbv} / \mathrm{sunlit}$ hour, another significant effect. Again, we note that the parameters used by Grooß and Müller (2003) differ somewhat from those of the original Match technique and our version of Match. We also note that the results of Grooß and Müller (2003) are based on analysis of model data while our results are based on analysis of the actual Match data. 


\subsection{Trajectory duration}

We next examine the effect of the duration of Match trajectories on the ozone loss rate calculations. Figure 5 shows the impact of including trajectories of durations of up to 14 days on the resulting ozone loss rates. As in Figs. 3 and 4, the blue lines represent AASE-2/EASOE data while the red lines represent SOLVE/THESEO 2000 data. The thick lines represent the mean values while the thin lines represent the means plus and minus one standard deviation as computed using the bootstrap technique. The vertical, solid black line at 10-days represents the maximum trajectory duration used in Rex et al. (1998, 2002).

As can be seen in Fig. 5, the shortest duration trajectories show the largest variation in ozone loss rates, both in the mean and in the large uncertainties. This result is not surprising given the fact that the shortest duration trajectories will be associated with the smallest exposures of the air parcels to sunlight. Since the sunlight exposure appears in the denominator of the ozone loss rate calculation, small absolute changes in these small numbers can lead to large changes in the resulting quotient.

Figure 5 indicates that no penalty is incurred with regards to the ozone loss rate calculations by including trajectories of durations of up to 14 days. In fact, Fig. 5 indicates that the uncertainties actually decrease by including these longer duration trajectories. Such a result suggests that the increased error that results from including longer, and hence more uncertain trajectories, is more than offset by the increased number of matches that result from considering more and longer trajectories. Although 14-day trajectory calculations appear at the upper end of the range of trajectory durations recommended in previous trajectory studies (e.g., Morris et al., 1995; Morris et al., 2000) we nevertheless recommend extending trajectory calculations to 14 days for future Match analysis.

\subsection{Vortex boundary}

We examine the impact of the PV value at which the vortex boundary is defined. Gradients in PV at the vortex boundary can be very strong, particularly in the Northern Hemisphere winter season. Since the precise vortex boundary is rarely clear, it is important to examine the impact of different choices on the ozone loss rate calculations. Furthermore, numerous trajectory studies (e.g., Waugh et al., 1994) have shown that the PV trail fades quickly, calling into question the viability of this filter for longer duration trajectories.

Figure 6 shows the sensitivity of the ozone loss rate to the definition of vortex boundary for data from AASE-2/EASOE in 1992. In producing these loss rates, we employ only the $\triangle \mathrm{PV}$ filter. (Note: we also ran this study with both the $\Delta \mathrm{PV}$ filter and the parcel spreading filter and found no statistically significant difference in the results). The solid colored lines represent loss rates calculated with our version of Match us-

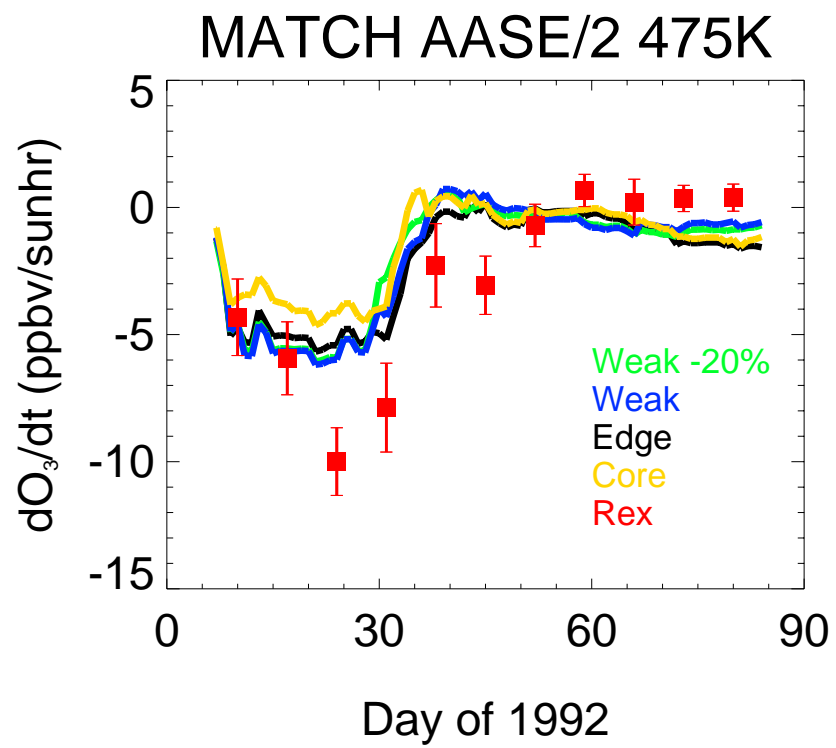

Fig. 6. The ozone loss rate as a function of day of the year is shown for the AASE-2/EASEO mission of 1992. The thick colored lines represent loss rates based on calculations using different definitions of the vortex boundary (see text). The red squares and associated error bars represent the ozone loss rates and uncertainties of Rex et al. (1998). The ozone loss rates are most sensitive to this choice in January.

ing four different definitions of the vortex boundary. The black curve is the standard, maximum MPV gradient boundary of Nash et al. (1996) labeled "edge." The "weak" (blue) and "core" (gold) definitions of the vortex boundary are defined by the nearest to the vortex boundary of the maximum and minimum, respectively, of the second derivative of the MPV. Finally, the "weak $-20 \%$ " is defined at the MPV value $20 \%$ less than the definition of the "weak" edge. The red squares and associated error bars represent the loss rate data from Rex et al. (1998).

Figure 6 indicates that loss rates can differ by up to $\sim 2$ ppbv/sunlit hour in January depending on the precise definition of the vortex boundary. After mid-February, loss rates seem to be consistent to within $\sim 1$ ppbv/sunlit hour. Systematic differences between the ECMWF meteorological data used by Rex et al. (1998, 2002) and the UKMO meteorological data, or differences in the precise definition of the PV value at the vortex edge, therefore, could result in differences in calculated ozone loss rates of up to $\sim 2 \mathrm{ppbv} / \mathrm{sunlit}$ hour in January.

\subsection{Solar zenith angle of day/night boundary}

Next, we examine the impact of the SZA definition for the day/night terminator. An examination of the sensitivity of the ozone loss rates to this quantity is relevant for more reasons than the precise SZA at which the chemistry turns on and off. High sensitivity to this quantity suggests that the 


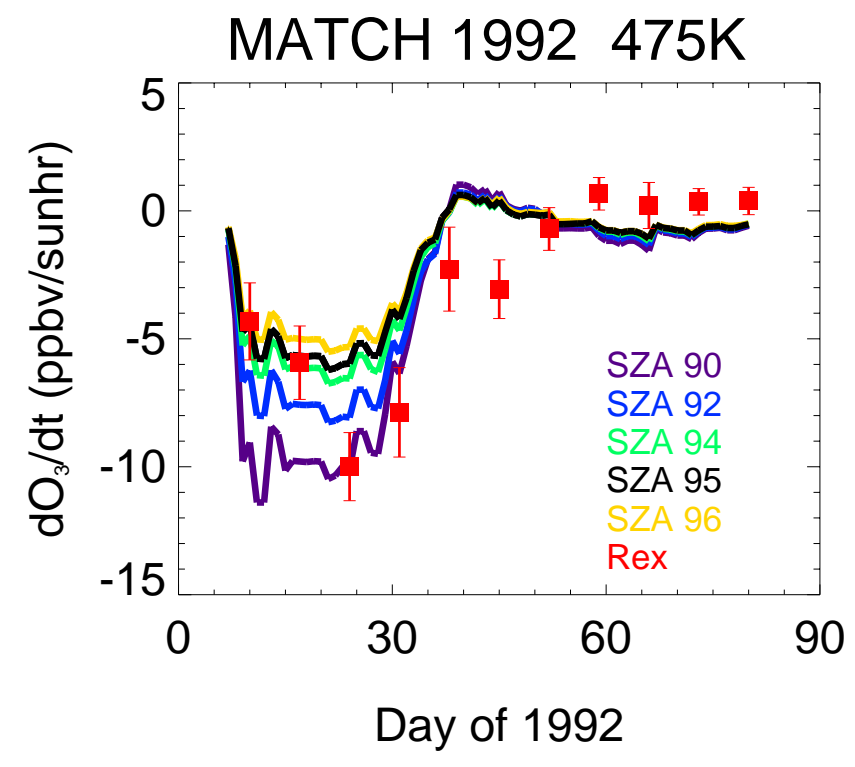

Fig. 7. As in Fig. 6 except that the thick colored lines represent loss rates based on the amount of solar illumination calculated using different values for the critical solar zenith angle at the day/night terminator. The red squares and associated error bars represent the ozone loss rates and uncertainties of Rex et al. (1998). The ozone loss rates appear quite sensitive to this choice in January and not very sensitive to this choice after mid-February.

precise trajectory path will affect the calculated ozone loss rate. Numerous analyses of trajectory modeling have indicated that while the path computed for any individual trajectory is not reliable beyond a few days, the results from an ensemble of trajectories provides useful and reliable information for much longer periods of time (e.g., Morris et al., 1995).

It has been suggested that such trajectory errors would likely cancel. However, let us consider a couple of possibilities for which they will not. The Arctic polar vortex is often found shifted off the pole (wave 1 disturbance) toward the European continent. During winter, latitudes above the Arctic Circle receive little to no sunlight. If the polar vortex is not shifted far enough away from the pole toward Europe in the analysis wind fields, the calculated trajectories will remain too far poleward, underestimating the actual amount of sunlight the parcels received and, hence, overestimating the ozone loss rates. As a second example, consider a vortex that is too small or shrinks in size in the wind field analysis after the initialization of the trajectory model as compared to the actual vortex behavior. As a result, the modeled air parcels again will receive less sunlight than the actual air parcels, leading to an overestimate of the ozone loss rates. In light of these two examples, we would argue that it is possible for a bias to exist in the estimation of the amount of sunlight air parcels receive in the model. Rex et al. (1998) consider the effect of a systematic drift in trajectories to higher or lower
PV values but conclude from their analysis that this effect would be negligibly small.

While a large number of trajectories is initialized in the Match technique, only a fraction actually are used to compute the ozone loss rates due to the numerous filters recommended and employed by Rex et al. (1998, 1999). According to its developers, the filters of the original Match technique eliminate $30-50 \%$ of the matches (M. Rex, personal communication, 2004). We find, however, that $80 \%$ of potentially matched sonde pairs and $>99 \%$ of potentially matched sonde observations are eliminated by the combined use of all the filters. If those trajectories that survive the filtering are inherently biased with regards to their position relative to the local day/night terminator, a bias in the amount of solar illumination may result, biasing the calculated ozone loss rates.

Figure 7 shows the sensitivity of the ozone loss rate to the definition of the terminator for data from the AASE2/EASOE time period. In producing these loss rates, we employ only the $\triangle \mathrm{PV}$ filter (see Sect. 2.2 for details). The solid colored lines represent loss rates calculated with our version of Match using a range of the SZA criterion from $90^{\circ}$ to 96 $6^{\circ}$. (Note that Fig. 7 indicates little difference between the ozone loss rates computed using a $94^{\circ} \mathrm{SZA}$ criterion and $96^{\circ}$ SZA criterion. Examining the difference in trajectories with SZA of $90^{\circ}$ versus SZA of $94^{\circ}$ leads to trajectory errors of about $4^{\circ}$ in latitude or $15^{\circ}$ in longitude for conditions in midJanuary at $65^{\circ} \mathrm{N}$ latitude. Trajectories near the vortex edge, where wind speed gradients are large, are more likely to experience such errors.) The red squares and associated error bars are again data from Rex et al. (1998). Rex et al. (1998, 2002) use a careful calculation of the exact SZA at which the sun disappears below the horizon at each air parcel altitude. In practice, that number varies very little from the $95^{\circ} \mathrm{SZA}$ that we employ in our version of Match. (In fact, a geometric calculation indicates a SZA for sunrise/sunset of $93.9^{\circ}$ at $15 \mathrm{~km}$ and $95.1^{\circ}$ at $25 \mathrm{~km}$, without atmospheric refraction effects.) We also recall that the uncertainty in the trajectories themselves likely will result in larger errors than those resulting from the use of $95^{\circ}$ as the SZA for the day/night terminator.

We can see in Fig. 7 that after about day 40 (9 February), the precise definition of this boundary has little impact on the calculated ozone loss rates, with variations between the ozone loss rates at $\mathrm{SZA}=90^{\circ}$ and that at $\mathrm{SZA}=96^{\circ}$ of only $\sim 1$ ppbv/sunlit hour. Before day 35 (4 February), however, we see large differences in the loss rate depending upon the precise SZA chosen, with the largest differences ( $\sim 6 \mathrm{ppbv/sunlit} \mathrm{hour)} \mathrm{occurring} \mathrm{in} \mathrm{January.}$

The fact that the calculated ozone loss rates show the greatest sensitivity to the SZA employed in January is not surprising. During January, the number of hours of solar illumination are quite small (and often zero) at high northern latitudes. By the middle of March, most of the same latitudes are receiving nearly $12 \mathrm{~h}$ of sunlight per day. As a result, 
the percent uncertainty in the amount of solar illumination is much greater for a given trajectory in January than in March.

It is also not surprising that the largest discrepancies in the ozone loss rates calculated by Rex et al. (1998, 2002) and those presented in this paper appear in January. Slight systematic differences in the trajectory calculations between the ECMWF winds used by Rex et al. (1998, 2002) and the UKMO winds used in this paper easily could lead to differences in calculated ozone loss rates of 4-6 ppbv/sunlit hour in January according to Fig. 7. In fact, we see that the largest published ozone loss rate from Rex et al. (1998) for late January 1992 falls near the curve computed using a day/night terminator with a SZA of $90^{\circ}$, although such a day/night terminator is unrealistic for the relevant ozone chemistry at the altitudes of our study.

To develop some sense of the importance of such differences, we examine the difference in sunlight exposures for the one of the 5 air parcels in each of our matched clusters with the most sunlight and the one with the least. We find a mean difference of $2.2 \pm 2.5 \mathrm{~h}$. A histogram of these differences shows a sharp peak at $0 \mathrm{~h}$ with a long tail extending out to 19 hours. Such differences in the amount of sunlight calculated along the trajectory affect the denominator in the loss rate calculations, resulting in potentially large changes in the ozone loss rate results.

We are led to the conclusion from Fig. 7 and the analysis of our trajectory data that the actual errors associated with the ozone loss rates calculated using Match are larger than the statistical error bars appearing in previous publications, especially for data in January. Furthermore, the original Match technique and our version of Match include many filtering criteria, which when combined result in the selection of only a small fraction of the Match data as qualifying events. Were not so many filters applied to the Match data, the likelihood of an unintentionally introduced selection bias would be substantially reduced. Figure 7 gives us cause for concern in interpreting Match results in January, particularly as related to the extremely large loss rates published by Rex et al. (1998) for AASE-2/EASOE during January 1992.

Again, we emphasize that this sensitivity study is a proxy for the importance of trajectory accuracy and the potential impact of trajectory uncertainties on the ozone loss rate calculations. A bias in the trajectory path could lead to an overor underestimate of the actual sunlight exposure and a corresponding under- or overestimate of the ozone loss rates.

\subsection{Sensitivity to population selection}

We examine Match results after removing all the Match filters except for the Match radius and the definition of the vortex boundary using MPV. Figure 8 shows that the ozone loss rates so calculated fall within the associated uncertainties as compared to those calculated with our version of Match using all the filters combined. Furthermore, the associated error bars for the ozone loss rates are comparable if not smaller

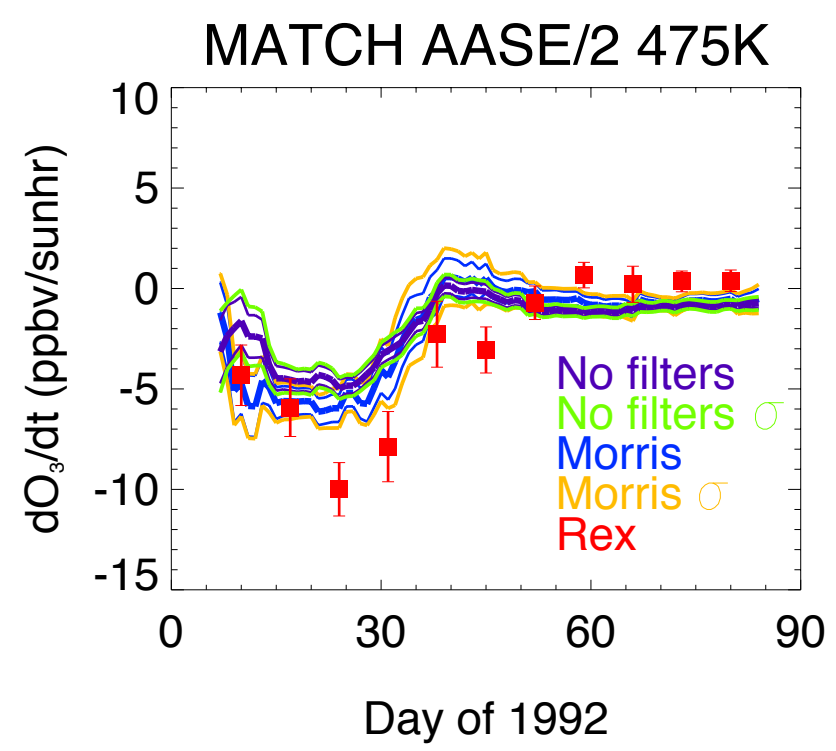

Fig. 8. This figure compares the results of our version of Match without applying filters except for the Match radius and the vortex boundary definition (purple with green error bars) against our version of Match with all the recommended filters (blue with gold error bars) and against the original Match results (red).

than those associated with the ozone loss rates determined in our version of Match (see discussion in Sect. 4 below). The largest differences appear in January, although even these differences are smaller than associated with the trajectory uncertainty as represented by the SZA sensitivity study.

Such results suggest that the five-fold increase in the number of matches which results from elimination of the Match filters more than offset the added uncertainty from the inclusion of more dubious matches in the ozone loss rate calculations. Furthermore, it is reassuring to include so many matches and achieve similar results. By not applying the Match filters, we can be sure that we have not accidentally thrown out some good data with the bad, and we are less likely to have unintentionally biased our results. It may be reasonable to conclude that Match could be as (if not more) effective by eliminating most (if not all) of its current data filters.

\subsection{Sensitivity to meteorological field choice}

We ran a series of diagnostic diabatic trajectories for the month of January 1992 using identical initialization schemes with both ECMWF and UKMO meteorological inputs. (Note that we use the ERA-40 ECMWF analysis rather than the 19level version used for the original Match studies of 1992.) Heating rates for both sets of data were calculated as in Rosenfield et al. (1994). We used 30 ozonesonde station launch sites in the Northern Hemisphere to initialize profiles of parcels spaced $5 \mathrm{~K}$ in potential temperature apart over 

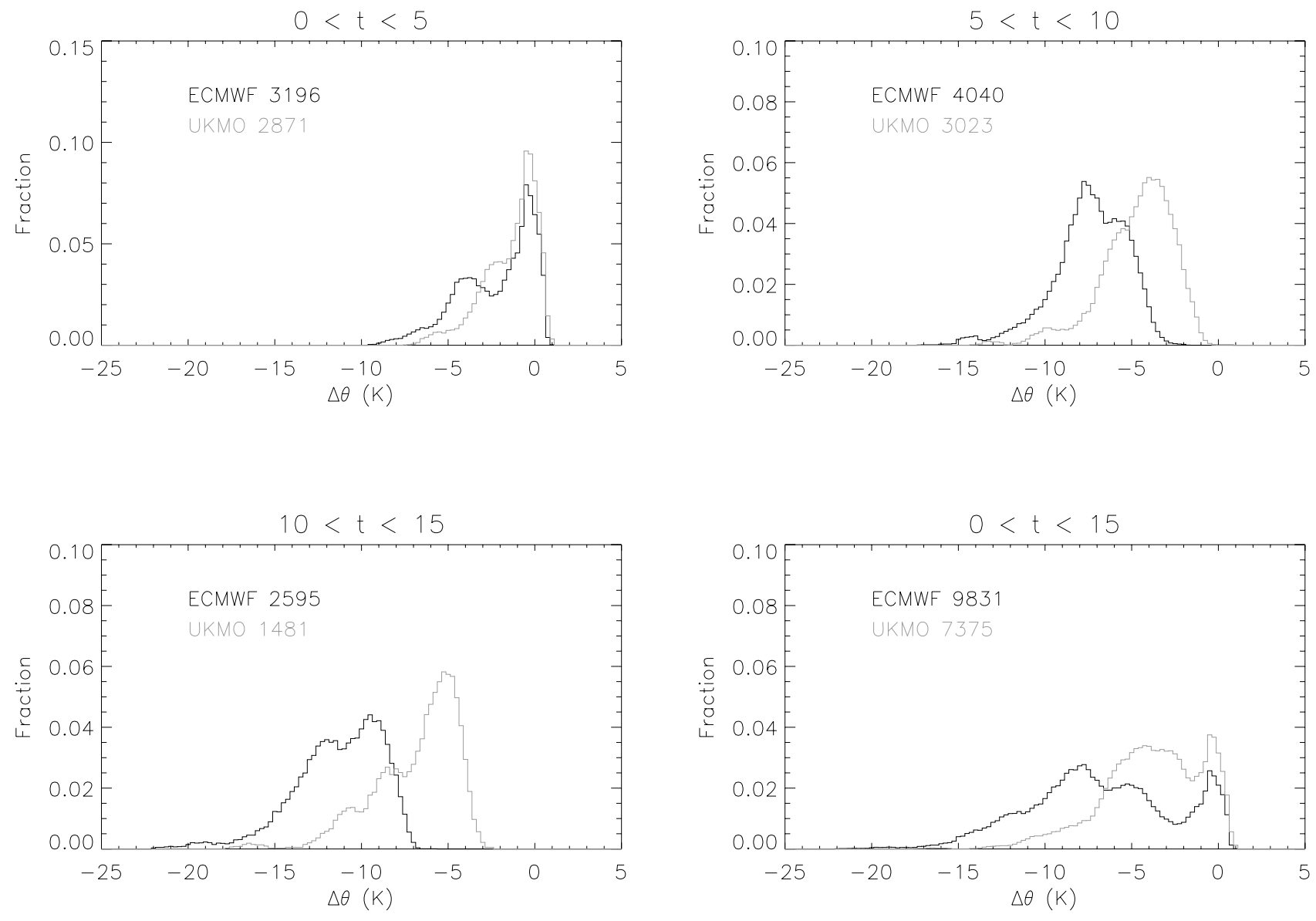

Fig. 9. The histograms show the difference in the descent for trajectories calculated using UKMO and ECMWF wind fields in January 1992 ending on the $475 \pm 10 \mathrm{~K}$ potential temperature surface. The initialization scheme is described in the text. The ECMWF fields result in more descent and more matches. Histograms are shown for trajectories of 0-5 days (upper left), 5-10 days (upper right), 10-15 days ( lower left), and $0-15$ days (lower right).

a range between 450 and $525 \mathrm{~K}$. Parcels were initialized at 12:00 UT every day of the month. Matches were identified when parcels passed within $475 \mathrm{~km}$ of another station location, were identified to be within the vortex (as defined using the weak vortex boundary condition of Nash et al., 1996), and were found at the $475 \mathrm{~K}( \pm 10 \mathrm{~K})$ potential temperature surface. Trajectories of duration $0-15$ days were included in our analysis.

We examined several diagnostic variables on the subset of trajectories that were found to match ozonesonde launch sites over three time scales: 0-5 days, 5-10 days, and 10-15 days. We included a filter for the PV variability along the back trajectory of $40 \%$.

Overall, the ECMWF run produced more matches on all time scales than did the UKMO run. The difference in the number of matches is especially noticeable for the longer trajectories, with UKMO producing $\sim 90 \%, \sim 75 \%$, and $\sim 57 \%$ of the number of matches as ECMWF for trajectories of duration $0-5,5-10$, and $10-15$ days respectively.
Histograms of the amount of sunlight exposure and trajectory length were nearly identical between the two meteorological data sets (not shown). The ECMWF trajectories, however, showed slightly less variability in PV along the trajectories than did the UKMO trajectories. This difference likely is due to the difference in time resolution of the data sets, with the ECMWF fields produced every $6 \mathrm{~h}$ and the UKMO fields produced only once daily, and also results in the trend in the difference in the number of matches cited above.

Finally, but potentially most importantly, the ECMWF matches experienced notably larger descent than their UKMO counterparts, on the order of $2-5 \mathrm{~K}$ more descent. Figure 9 shows a series of histograms of the amount of descent experienced by ECMWF and UKMO air parcels for trajectories of differing duration ( $0-5$ days, 5-10 days, $10-15$ days, and $0-15$ days). Given the sharp gradients in the ozone profiles near $475 \mathrm{~K}$, such differences could lead to larger "loss" rates when calculating matches with the ECMWF 
fields as compared to calculations with UKMO fields. The fact that trajectories appear to be quite sensitive to the exact meteorological data set used to drive the trajectory model adds yet another element to the uncertainty of the ozone loss calculation results.

In summary, our sensitivity studies indicate that the PV difference along the back trajectory appears to be a justifiable filter, and that the definitions of the vortex boundary and of the SZA at the day/night terminator can have a significant impact on the ozone loss rate calculations, especially in January. (The SZA sensitivity study serves as a proxy for the sensitivity of the loss rate calculations to the precise trajectories, which for any individual air parcel are highly uncertain after only a few days as shown by Morris et al., 1995.) Furthermore, the choice of meteorological analysis used to drive the trajectory model can have an important impact on the results. The remainder of the filters, however, do not appear to significantly impact our ozone loss rate calculations.

\section{Results}

In this section, we present results from our version of Match (see earlier discussion for differences from the original version of Match) and from the PV/Theta analysis. Our version of Match yields loss rates of similar magnitude to those published by Rex et al. $(1998,2002)$, although we are unable to reproduce the largest loss rates in January 1992 on the $475 \mathrm{~K}$ surface without unrealistically altering the SZA for the terminator (see the sensitivity study above). We also find somewhat smaller loss rates in March 2000 on the $450 \mathrm{~K}$ and $500 \mathrm{~K}$ surfaces than those shown by Rex et al. (2002). Our loss rates do agree well with numerous other studies including model simulations, as we outline below. In each case, as in the original Match studies, results shown on a given Theta surface include all matches occurring with in $\pm 10 \mathrm{~K}$ of that Theta surface.

\subsection{Results from our version of Match}

Figure 10 shows the ozone loss rate as a function of time for the SOLVE/THESEO 2000 period on the $500 \mathrm{~K}$ potential temperature surface. Each black dot in the figure represents one possible outcome for the ozone loss rate calculation (as described above and below).

As an example of an ozone loss rate calculation, Fig. 11 shows the Match data from the 20-day period 12 January1 February 2000. We randomly pick half of these matches from which to compute the line-of-best fit. The randomly selected half appears as the solid red squares while the unused data are open black squares. For the red data points, we find a line-of-best-fit with a slope of $-8.09 \pm 1.48 \mathrm{ppbv} / \mathrm{sunlit}$ hour. Note that this loss rate is substantially different from that calculated by using all the data of $-3.82 \pm 1.14 \mathrm{ppbv} / \mathrm{sunlit}$ hour. The fact that the two slopes are $\sim 3$ standard deviations

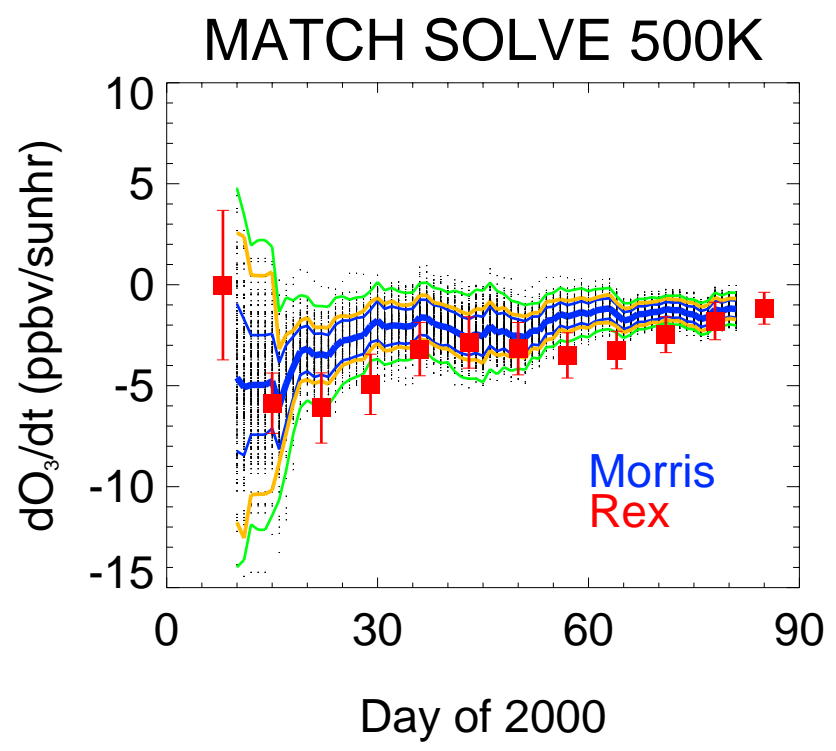

Fig. 10. The ozone loss rate as a function of day of the year for the SOLVE/THESEO 2000 mission period of 2000 on the $500 \mathrm{~K}$ potential temperature surface. The black dots represent possible loss rates calculated with our version of Match (see text). The thick blue line is the mean of these data while the thin blue lines represent the mean plus and minus one standard deviation of the black dots. The gold lines represent the mean plus and minus one standard deviation computed from the bootstrap technique for a single iteration (see text). The green lines represent the mean plus and minus one standard deviation computed from the statistical error (blue lines) plus an estimate of the uncertainty in the Match technique (see text). The red squares are data from Rex et al. (2002) for the same time period. Error bars associated with the Rex data are one standard deviation as calculated with the standard statistical approach.

apart suggests that such an outcome should be extremely unlikely. Yet the difference in the results highlights the importance of the specific subset of matches upon which the loss rates are calculated. Including or excluding one sonde could dramatically alter the slope of the line-of-best-fit and, hence, the ozone loss rate reported.

Subsets of data like that shown in Fig. 11 are iteratively and randomly selected for each day ( \pm 14 days for AASE2/EASOE or \pm 20 days for SOLVE/THESEO 2000). These subsets permit us to explore the range of possible ozone loss rates. Figure 11 represents one possible outcome. The slope computed using the data highlighted by the red squares in Fig. 11 leads to one black dot in Fig. 10. The random subsets are generated 200 times for each day. (Our tests indicate that 200 subsets is a sufficiently large number to result in stationary statistics.) Each of the black dots in Fig. 10 therefore represents the loss rate as computed from one such subset. The mean results (the average of the black dots) is indicated by the thick blue line. The thin blue lines in Fig. 10 represent the average plus and minus one standard deviation as computed using the scatter of the black dots. 


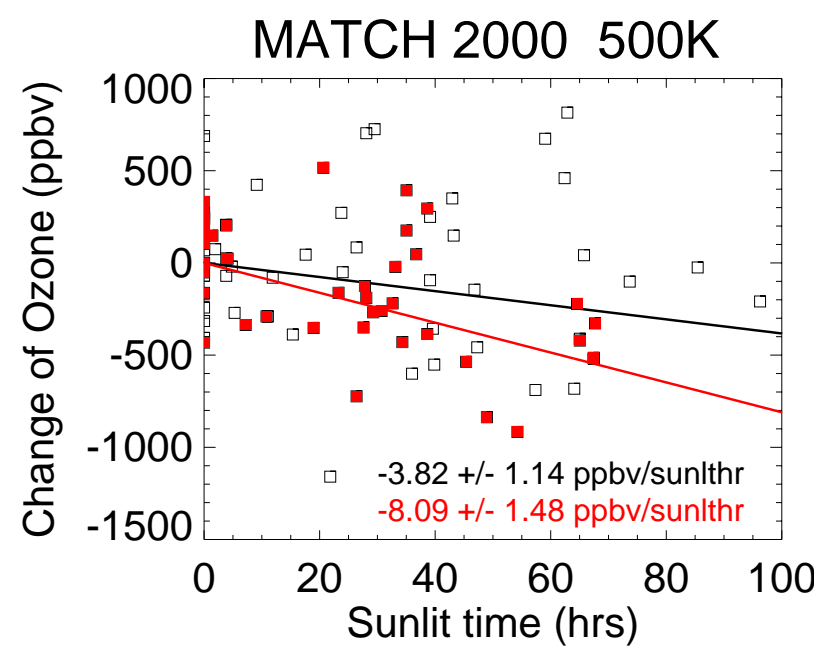

Jan 12 - Feb 1

Fig. 11. An example of how the ozone loss rate is calculated for SOLVE/THESEO 2000 on the $500 \mathrm{~K}$ potential temperature surface for the 20-day period of 12 January-1 February 2000. Each black and red square represents a change in ozone and amount of sunlit time for a single match. The red squares are randomly selected and number half of the matches. The solid black line is the line-of-best fit to the entire data set (both black and red squares). The solid red line is the line-of-best-fit to the red squares only. As can be seen, the calculated loss rate can be highly dependent upon the subset of data used for the calculation.

The thick gold lines in Fig. 10 represent the average result (thick blue line) plus and minus one standard deviation as computed using the bootstrap technique (described above in Sect. 2.3) to exactly one realization of the random subsets of data (e.g., the subset highlighted in red in Fig. 11). The gold lines therefore represent a different and independent estimate of the uncertainty in the data as compared with the thin blue lines which are generated from the scatter of the ensemble of results. As expected, the uncertainty from the bootstrap technique has a similar magnitude to that computed from the scatter of the data.

The green lines in Fig. 10 represent an estimate of the average result (thick blue line) plus and minus one standard deviation of the estimated total uncertainty. To compute the estimated total uncertainty, we add the statistical uncertainty to the uncertainty in the computed loss rates generated by the uncertainty in the trajectories themselves. To estimate the uncertainty in the trajectories, we examine the impact on the ozone loss rates of changes in the SZA at which the day/night terminator is defined (see the sensitivity study above). We also add in a term to account for slightly different definitions of the vortex boundary (see the sensitivity study above). The green lines are our best estimate of the total error in the loss rates as computed with our version of the Match technique. Rex et al. (1998) examined a series of possible systematic ef-

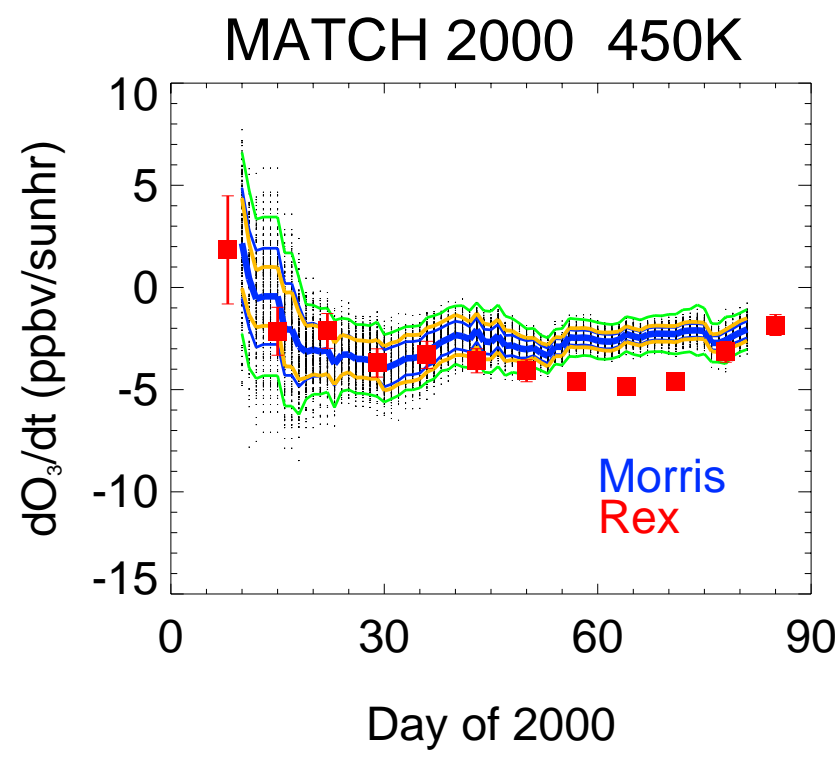

Fig. 12. Same as Fig. 10 except for the $450 \mathrm{~K}$ potential temperature surface during SOLVE/THESEO 2000.

fects including systematic trajectory drift, systematic heating rate calculation offsets, and the vertical and horizontal diffusion of air parcels. In each case, they come to the conclusion that these errors are likely small, a result somewhat different than what appears for the January data in our Fig. 10, for which the green lines indicate larger uncertainties than the statistical error bars.

The solid red squares in Fig. 10 represent the loss rates as calculated by Rex et al. (2002), and their associated error bars are one standard deviation from the mean as computed using standard regression error algorithms. The error bars associated with the "Rex" data should be compared to the gold or thin blue lines, since these error estimates are all measures of the statistical error.

The statistical errors associated with the original Match data are similar in magnitude to the scatter in the loss rate calculations based on the subsets of data as seen in the black dots and thin blues lines of Fig. 10. However, the total uncertainty in the loss rates (green lines) is larger than that estimated by the standard regression routine (quoted with the slopes above for Fig. 11) due to the presence of other errors (see above). Furthermore, because the regression is forced through the origin, the uncertainty estimate associated with the slope necessarily will be reduced as compared to the uncertainty in the estimate of the slope when the line-of-best fit has two free parameters (slope and intercept) as calculated with the standard routines. (We also note that if we perform a two-parameter regression rather than forcing each line-ofbest-fit through 0 , the magnitudes of our loss rates change. If our analysis includes a bias of which we are not aware, forcing the regression through zero may well be inappropriate.) 
For the $500 \mathrm{~K}$ Theta surface during SOLVE/THESEO 2000 , we find reasonably good agreement between the magnitudes of the loss rates published by Rex et al. (2002) and those found in our version of Match. In late January and early February (days 15-35) and again in late February and early March (days 56-70), however, our results seem to indicate somewhat smaller loss rates than those of Rex et al. (2002). Such differences may be due, at least in part, to the differences in meteorological wind fields and heating rates, as delineated in Sect. 2.3 above.

Figure 12 shows the results from our version of Match for the $450 \mathrm{~K}$ surface during SOLVE/THESEO 2000. While we see generally good agreement for January through mid February, we find that during days 56-75, our version of Match produces smaller ozone loss rates than those of Rex et al. (2002). Furthermore, the larger loss rates of Rex et al. (2002) in early March 2000 fall outside the statistical error bars of the Rex et al. (2002) data (red) and the bootstrap (gold) and total (green) error estimates for our data. Given the results of our diagnostic comparison of the UKMO and ECMWF meteorological fields (see Sect. 3.7), these differences may be due to the larger descent rates associated with the ECMWF trajectories. It is also possible that such differences are indicative of uncertainties inherent in the Match technique for which we have not yet accounted or undetected biases in one approach or the other. We believe, however, that both methods have still underestimated the actual errors of the Match technique.

Figure 13 shows the results for the $475 \mathrm{~K}$ surface during the AASE-2/EASOE period of January through March 1992. We find generally good agreement throughout the period with the notable exception of days 20-35 during which Rex et al. (1998) report persistent losses of a magnitude not observed in any other study of the Arctic and that are difficult to reproduce with our current understanding of stratospheric chemistry (Sander et al., 2003; Becker et al, 1998; Solomon, 1999). Our data show large loss rates during this time period as well, but of half the magnitude. The combined uncertainty of the Rex et al. (1998) data and our bootstrap error estimates is larger than the difference in the results. However, the Rex et al. (1998) data points fall within the combined uncertainty when using our estimate of the total uncertainty (green lines), suggesting this estimate might be reasonable for this data.

Figure 13 also shows a discrepancy for the loss rates in mid-February, again with our model showing less loss. The disagreement at this time may be related to the differences between our vortex boundary definition using UKMO meteorological data and that of Rex et al. (1998) using ECMWF meteorological data (see the sensitivity study above).

\subsection{Comparisons with other studies}

Newman et al. (2002) published a summary of results for integrated ozone loss during the SOLVE/THESEO 2000 campaign on the $450 \mathrm{~K}$ potential temperature surface. Their Ta-

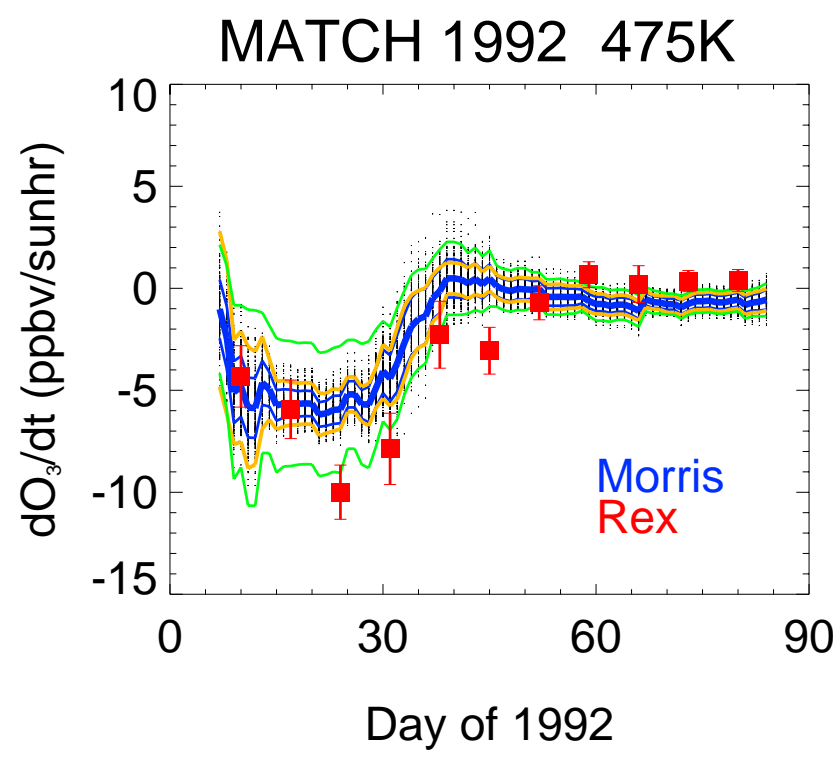

Fig. 13. Same as Fig. 10 except for the $475 \mathrm{~K}$ potential temperature surface during AASE-2/EASOE (1992).

ble 8 lists integrated ozone losses over the period 20 January12 March 2000 from 14 different studies. Losses ranged from $0.7 \mathrm{ppmv}$ (Klein et al., 2002) to $2.3 \mathrm{ppmv}$ (Santee et al., 2000), with an average loss of $1.5 \pm 0.4$ ppmv. Rex et al. (2002) use the original Match technique and report an integrated ozone loss of $1.7 \pm 0.2 \mathrm{ppmv}$ over the same time period. Our version of Match yields an integrated ozone loss of $1.3 \pm 0.2 \mathrm{ppmv}$. (We note that the integrated loss depends upon the definition of the vortex boundary.) Lait et al. (2002) use a PV/Theta approach to estimate ozone loss for SOLVE/THESEO 2000 and find an integrated ozone loss over this period of $1.7 \pm 0.3 \mathrm{ppmv}$. Tilmes et al. (2004) used tracer-tracer correlations to produce an estimate of ozone loss from early in the winter of 1999-2000 through March. Using HALOE HF data, they found an ozone loss of $\sim 1.8 \pm 0.8$ ppmv (estimated from their Fig. 9), and using $\mathrm{HALOE} \mathrm{CH}_{4}$, they found an ozone loss of $\sim 1.6 \pm 0.5 \mathrm{ppmv}$ (estimated from their Fig. 10).

No similar compilation has been published for the AASE2/EASOE campaign for which Rex et al. (1998) and von der Gathen (1995) published their largest Arctic ozone loss rates. Based on the data of Rex et al. (1998), integrated chemical ozone loss for air parcels that descended from $500 \mathrm{~K}$ on 1 January to $460 \mathrm{~K}$ on 29 February 1992 is $1.2 \pm 0.3$ ppmv. For the same period, we find an integrated chemical ozone loss at $475 \mathrm{~K}$ of $0.8 \pm 0.2 \mathrm{ppmv}$ using our version of Match. Using the PV/Theta approach, the integrated loss is $0.4 \pm 0.8 \mathrm{ppmv}$ at $475 \mathrm{~K}$ and $0.8 \pm 0.7 \mathrm{ppmv}$ at $450 \mathrm{~K}$.

Becker et al. (2000) used a box model to calculate ozone loss rates for the winter/spring of 1991-1992. They found that while they are able to reproduce the Match loss rates from mid-February through March, their loss rates for the 
period at the end of January are significantly smaller, by more than a factor of 2, a result similar to the discrepancy we find in this study between the original Match results and the results from our version of Match. The ozone loss rates of Becker et al. (2000) peak at about 4 ppbv/sunlit hour around 17 January with no indication of the large spike in loss rates found in Rex et al. (1998) for late January. The ozone loss rates of Becker et al. (2000), however, are in quite good agreement with our results for this time period. From their Fig. 2, we see that for air parcels descending to $466 \mathrm{~K}$, the ozone mixing ratio changes from about $3.85 \mathrm{ppmv}$ on 1 January to 2.80 ppmv on 29 February 1992, a loss of 1.05 ppmv.

Rex et al. (2003) attempt to explain the large ozone loss rates seen in Match. They use a photochemical box model run along Match trajectories. Assuming total activation of chlorine, they report a maximum loss rate at $475 \mathrm{~K}$ in January 1992 of around $5 \mathrm{ppbv} / \mathrm{sunlit}$ hour. Such a result, while smaller by a factor of two than the reported ozone loss rates from the original Match technique, is in agreement with the maximum loss rate found in our version of Match.

Lucic et al. (1999) use a PV/Theta approach to estimate time-integrated ozone loss at $475 \mathrm{~K}$ during the first 20 days of January 1992 when the vortex is well isolated (Plumb et al., 1994). They found a loss of $0.32 \pm 0.15 \mathrm{ppmv}$, which agrees with the ozone loss calculation from both the original Match approach of $0.3 \pm 0.2 \mathrm{ppmv}$ and our version of Match of $0.34 \pm 0.16$ ppmv. For the same period, our PV/Theta analysis indicates a loss of $0.5 \pm 0.8$ at $475 \mathrm{~K}$.

Browell et al. (1993) report results from their differential absorption lidar (DIAL) study. They observe no polar stratospheric clouds (PSCs) within the polar vortex during the winter of 1991/1992, but do report the development of water ice (type II) PSCs just outside the vortex between Norway and Iceland on 19 January 1992. We note that Rex et al. (1998) report their largest ozone loss rates five days later on 24 January 1992. The development of PSCs in this region place them upwind of a number of the European ozonesonde stations included in the Match study, perhaps impacting the results.

Using a combination of their lidar observations and a determination of the total amount of diabatic descent from in situ observations of trace gas species (e.g., Podolske et al., 1993), Browell et al. (1993) find a chemical ozone loss of about $23 \%$ near $460 \mathrm{~K}$ between January and March 1992. This percentage translates to about $0.7 \mathrm{ppmv}$ of ozone, again in agreement with our integrated Match result of

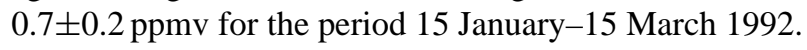

Profitt et al. (1993) use a trace gas - ozone correlation using $\mathrm{N}_{2} \mathrm{O}$ to deduce ozone loss in the Arctic winter vortex in 1991-1992. They report in their Table 2 the largest ozone loss rates on 20 January 1992 of 25.45 ppbv/day. Assuming $6 \mathrm{~h}$ of sunlight per day (their assumption), this translates to about $4.2 \mathrm{ppbv} / \mathrm{sunlit}$ hour. Loss rates of $0.2-2.4 \mathrm{ppbv} / \mathrm{sunlit}$ hour are reported throughout the rest of the winter season. These loss rates agree reasonably well with the results from our version of Match, but the largest loss rate is more than a factor of two smaller than that derived from the original Match technique and published by Rex et al. (1998) and von der Gathen (1995).

Tilmes et al. (2004) also use a trace gas - ozone correlation using HALOE HF and $\mathrm{CH}_{4}$ to deduce ozone loss in the Arctic winter vortex in 1991-1992. Using both HALOE $\mathrm{HF}$ and $\mathrm{CH}_{4}$, they find an ozone loss from early winter to March of $\sim 1.2 \pm 0.3$ ppmv (estimated from their Figs. 9 and 10 ), somewhat larger than our 15 January to 15 March loss of $0.7 \pm 0.2$ ppmv.

Salawitch et al. (1993) use in situ observations of ClO and $\mathrm{BrO}$ from AASE II in conjunction with a photochemical model to determine ozone loss rates. Averaged over the vortex, they find an ozone loss rate in January of $0.4 \%$ per day, notably lower than the ozone loss rates they calculate along the ER-2 flight track, which peak at $1.4 \%$ per day (about $7.5 \mathrm{ppbv} / \mathrm{sunlit}$ hour assuming $6 \mathrm{~h}$ of sunlight, their assumption). They report an integrated ozone loss over the entire winter at $470 \mathrm{~K}$ of $0.7 \mathrm{ppmv}$. Again, these calculated ozone loss calculations are consistent with our finding of $1.0 \pm 0.3 \mathrm{ppmv}$ of ozone loss integrated over the period from 1 January through 31 March 1992 . The large difference between the vortex averaged loss rate and the peak loss rate found by Salawitch et al. (1993) suggests a possible explanation for the large ozone loss rates found in Rex et al. (1998): that ozone loss rates in specific air parcels may briefly yet greatly exceed the rate characteristic of a larger geographic area.

Braathen et al. (1994) perform an analysis of ozonesonde data from EASOE and find an average ozone loss rate inside the polar vortex of $0.13 \pm 0.08 \%$ per day for air at $475 \mathrm{~K}$ during the period 9 January-12 March 1992. Rex et al. (1998) relate that the peak ozone loss rates found using the technique of Braathen et al. (1994) yield ozone loss rates of $0.8 \%$ per day in mid January, but that such rates are underestimated by $0.1-0.35 \%$ per day. Correcting for such an underestimate, the peak loss rates become $0.9-1.2 \%$ per day, in good agreement with the maximum rates reported using ER-2 data Salawitch et al. (1993) above.

In summary, a large number of studies and analyses of the ozone losses during the AASE-2/EASOE mission in the winter of 1991-1992 (January through March) converge on roughly the same answers: an integrated ozone loss for the January through March period of 0.7-1.2 ppmv between $450 \mathrm{~K}$ and $475 \mathrm{~K}$ with peak loss rates in mid-January of 4-8 ppbv/sunlit hour, with the exception of the original Match results which suggest a peak loss rate of greater than $10 \mathrm{ppbv} / \mathrm{sunlit}$ hour. Photochemical models seem to agree well with the observational data and the results from our version of Match. 


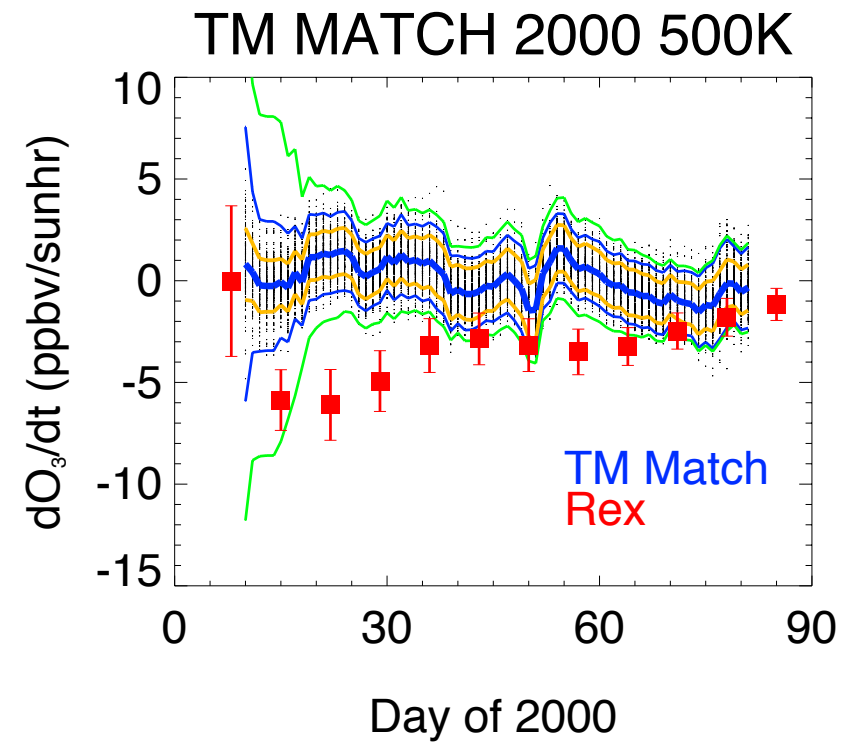

Fig. 14. As in Fig. 10 except using the trajectory mapping approach (see text) for SOLVE/THESEO 2000 on the $500 \mathrm{~K}$ potential temperature surface.

\section{A trajectory mapping approach to Match}

\subsection{Methodology}

We have noted that employing the various filters in our version of Match effectively eliminates $80 \%$ of the possible matched sonde pairs and $>99 \%$ of the matched sonde observations. We therefore present an alternate approach to Match that does not rely upon such filters. This approach follows from the development of trajectory mapping as employed by Morris et al. (1995, 2000), Danilin et al. (2000), and others and was first developed by Pierce et al. (1994). In this approach, all advected air parcels that arrive within the specified Match radius and within an appropriate vertical distance of the new observation are considered matches with the new ozone measurement. We present this approach as a potential alternative to the original Match technique. An extensive validation and assessment of this approach, however, is beyond the scope of this paper.

To determine an appropriate vertical scale over which to search for matches, we calculate the autocorrelation of the noise in the ozone profile. Typically, this vertical scale is about $1 \mathrm{~km}$, very similar to the $5 \mathrm{~K}$ vertical spacing of the Theta surfaces used in the original Match technique. In the trajectory mapping approach, however, we do not compare a single observation to a single observation. Rather, we use all matches in the cylindrical volume of space around the new observation, $\sim 1 \mathrm{~km}$ in height and with a radius of $475 \mathrm{~km}$ (1992) or $400 \mathrm{~km}$ (2000) (to duplicate the Match radius criteria of Rex et al., 1998, 2002). We also permit all parcels initialized in a cluster for each ozonesonde observation to match

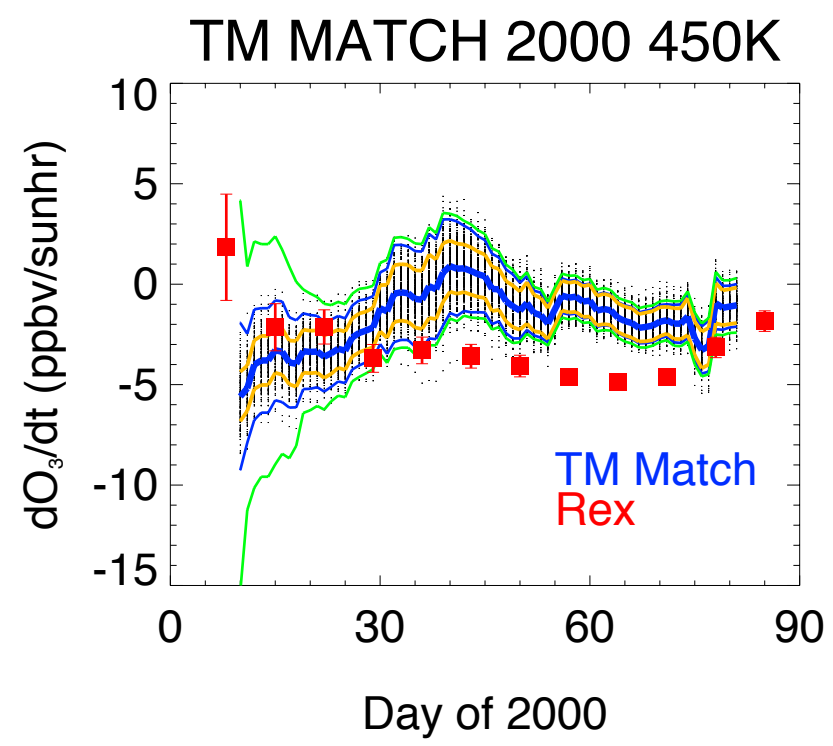

Fig. 15. As in Fig. 10 except using the trajectory mapping approach (see text) for SOLVE/THESEO 2000 on the $450 \mathrm{~K}$ potential temperature surface.

in this approach, not just the central parcel. With the large number of qualifying Matches in this alternate approach and with the elimination of the plethora of filters, the statistics for the calculated ozone loss rates are more robust.

Finally, we use a two-parameter fit to determine the ozone loss rates rather than forcing the fits through the origin. Although we certainly agree that no chemical ozone loss should occur if the parcel is not exposed to sunlight, our modeling can only estimate the amount of sunlight to which a parcel has been exposed. Possible biases in these calculations due to trajectory errors could lead to fits that do not pass through the origin. Therefore, for the trajectory mapping (TM) Match results, we allow the fit to have a non-zero intercept. We believe the trajectory mapping approach represents a statistically defensible alternative to the original Match technique.

\subsection{Results}

Figures 14,15 , and 16 show the ozone loss rates as a function of time for the $500 \mathrm{~K}$ and $450 \mathrm{~K}$ potential temperature surfaces during SOLVE/THESEO 2000 and for the $475 \mathrm{~K}$ potential temperature surface during AASE-2/EASEO (1992) respectively. Our data appear in black, blue, gold, and green (as before) while the Rex et al. $(2002,1998)$ data appear in red.

In Fig. 14, we see that on the $500 \mathrm{~K}$ surface, ozone loss rates remain near 0 throughout the study period. Such results agree with the first and last data points of Rex et al. (2002). However, the ozone loss rates in general are smaller in magnitude than those found using the original Match technique (Rex et al., 2002) for the rest of the study period. From mid 


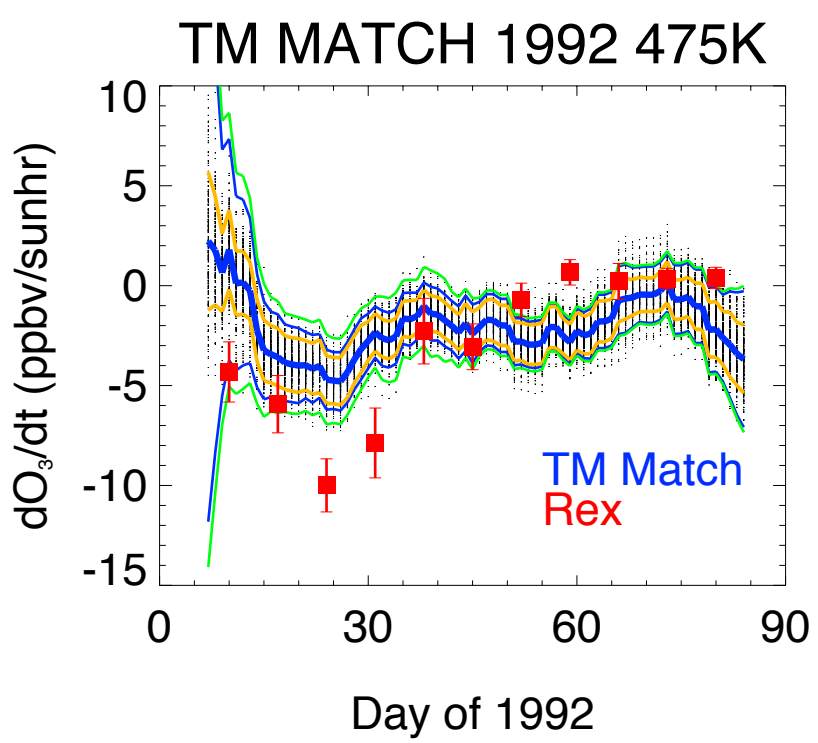

Fig. 16. As in Fig. 10 except using the trajectory mapping approach (see text) for AASE-2/EASOE on the $475 \mathrm{~K}$ potential temperature surface.

February ( day 40$)$ through the end of March, the ozone loss rates typically agree within $\sim 1 \sigma$ with those found in the original version of Match. From day 15 through day 40, however, the TM Match loss rates are different by more than the statistical $1 \sigma$ uncertainty. Comparing the TM Match results with the ozone loss rates from our version of Match (shown in Fig. 10), however, we find that the TM Match loss rates are within $1 \sigma$ for most of the study period with the exception of the first half of January. These differences suggest that the uncertainty of the ozone loss rates may be even larger than the estimates shown and that the Match approach may not be appropriate under conditions of low sunlight such as found each January in the Arctic.

Figure 15 shows the loss rates calculated on the $450 \mathrm{~K}$ surface for SOLVE/THESEO 2000. On this Theta surface, the loss rates agree well with those of the original Match technique in mid to late January and again in mid to late March. From mid February to mid March, however, the TM Match loss rates are significantly less than those found in the original Match technique. In comparison with the results from our version of Match (shown in Fig. 12), the TM Match results agree to within $1 \sigma$ for most of the study period with the exception of early to mid January, at which time the TM Match loss rates are higher. Again, the difference in January results between the TM Match and the original Match technique suggest the difficulty associated with calculating loss rates under low sunlight conditions.

As a check on the loss rates indicated by the trajectory mapping approach, we again examine the integrated loss over the period of 20 January-12 March. The trajectory mapping approach results in a change of $-0.5 \pm 0.2 \mathrm{ppmv}$ of ozone, a result that is clearly low compared to the ozone losses for this period shown in Table 8 of Newman et al. (2002) as well as the results we found in our version of Match $(-1.3 \pm 0.2 \mathrm{ppmv}$ over the same period). While such comparisons are disappointing, they suggest that the uncertainties associated with TM Match may still be too small. Furthermore, since we believe that the TM Match approach is statistically more defensible due to its weighting scheme and inclusion of more viable matches, the poor agreement calls into question the efficacy of the Match approach.

Finally, Fig. 16 shows the loss rates calculated on the $475 \mathrm{~K}$ surface for the AASE-2/EASOE mission in 1992. Recall that the launches in 1992 were not coordinated as a part of Match, which resulted in far fewer coincidences in 1992 compared with $2000(\sim 1100$ versus $\sim 2600)$. The TM Match results indicate the largest ozone loss rates occur in late January and again in late March. From mid February through the end of March, the TM Match results generally agree with those of the original Match technique, with the exception of the data point at the end of February. In January, TM Match indicates smaller loss rates than the original Match. In comparison with the results from our version of Match (shown in Fig. 13), TM Match shows good agreement throughout the study period, generally falling within $1 \sigma$ with the exception of late March.

Integrated loss over the period 1 January through 29 February 1992 using the ozone loss rates from TM Match indicate a total loss of $0.8 \pm 0.3 \mathrm{ppmv}$, a result in good agreement with that found using our version of Match $(0.8 \pm 0.2 \mathrm{ppmv}$, see above) and about twice that found using the PV/Theta approach $(0.4 \pm 0.2 \mathrm{ppmv}$, see above).

Differences in the results achieved using the trajectory mapping approach and the original Match technique may not be statistically significant if we appropriately take into account and estimate all the sources of error inherent in both approaches. As alluded to in the earlier discussion, evidence from our study suggests that at present, the published uncertainties for the original Match technique and those indicated by our error bars underestimate, often substantially and systematically, the true uncertainties in the Match technique. The effects are particularly noticeable in January, a month during which very little sunlight is available and for which the discrepancies with our results and with other studies are the largest. The results from the TM Match approach, which we believe to be statistically defensible, certainly often reveal insignificant loss rates.

\section{Summary and conclusions}

We have attempted to reproduce the Match studies for the AASE-2/EASOE (1992) and SOLVE/THESEO 2000 mission periods. We first set out to recreate the Match technique. Although we are unable to reproduce the January 1992 loss rates published by Rex et al. (1998) and have 
somewhat smaller loss rates in March 2000 than published in Rex et al. (2002), the remainder of the comparison shows good agreement with the original results. Furthermore, our sensitivity studies indicate that although the statistical uncertainties agree well with those of the original Match studies, the actual uncertainties associated with the ozone loss rates may be larger than those published, especially during the month of January for which the results are extremely sensitive to the amount of solar illumination and thus to the precise trajectory followed by each air parcel.

To assess the equivalence of our version of the Match technique with the original, we attempt to reproduce Fig. 6 of Rex et al. (1998), which shows the linear relationship between the ozone change and the amount of sunlight to which the air parcel has been exposed. Our data in Fig. 2 indicates general agreement with the original data, although our data seem systematically to reveal less ozone loss than the data from Rex et al. (1998).

Our sensitivity studies indicate that the only Match filter that appears to impact significantly the Match results is that associated with the PV variability along the back trajectory. Filtering out matches that show more than $40 \%$ variation in PV along the calculated back trajectory appears to be warranted. Trajectories of up to 14 days can be included in Match analyses with no apparent negative impact on the ozone loss rate calculations. This result is consistent with the methodology of Schoeberl et al. (2002), which uses a continuous data injection/trajectory approach with trajectories of up to 90 days duration and found a loss rate of $1.63 \pm 0.3 \mathrm{ppbv}$ between 20 January and 12 March 1992. (Note that here and throughout this summary, quoted statistical uncertainties are at the one standard deviation level.)

In addition, the parcel spreading filter may be unnecessary. Our data indicate that parcels that have spread by up to $2500 \mathrm{~km}$ can be included in the Match ozone loss calculations with little negative impact on the results.

Our sensitivity studies also indicate that the precise definition of the vortex boundary can have an impact on the calculated ozone loss rates on the order of 1-2 ppbv/sunlit hour, with the largest effects seen in January.

We indirectly examine the sensitivity of the ozone loss rate calculations to the precise trajectory of the air parcels by varying the SZA at which the day/night terminator is defined. We find that this parameter also can have a large impact on the ozone loss rate calculations, particularly in January when we observe differences of 4-6 ppbv/sunlit as we varied the SZA at the day/night terminator from $90^{\circ}$ to $96^{\circ}$.

A diagnostic comparison of trajectories generated using UKMO and ECMWF meteorological fields for January 1992 indicates that ECMWF experience $2-5 \mathrm{~K}$ more descent, on average, than their UKMO counterparts. Further investigation of the differences in meteorological fields is warranted but is beyond the scope of this paper. Like the original version of Match, our version indicated little to no loss in dark hours along the trajectories, bolstering our confidence in our results.

When integrating our results for the SOLVE/THESEO 2000 campaign, we find good agreement for the accumulated ozone loss over the January to March period with other studies shown in Newman et al. (2002). Our version of Match yields an integrated ozone loss of $1.3 \pm 0.2 \mathrm{ppmv}$ as compared to the loss from the original Match technique of $1.7 \mathrm{ppmv} \pm 0.2 \mathrm{ppmv}$. While our ozone loss is somewhat smaller in magnitude than that of Rex et al. (2002), it is within in the range of published loss rates $(0.7-2.3 \mathrm{ppmv})$.

We use the PV/Theta approach of Lait et al. (2002) on the data from 1992 and find an integrated loss of $0.8 \pm 0.7 \mathrm{ppmv}$ at $450 \mathrm{~K}$ and of $0.4 \pm 0.8$ at $475 \mathrm{~K}$ over the period 1 January29 February 1992. Using our version of Match, we find a loss of $0.8 \pm 0.2 \mathrm{ppmv}$ at $475 \mathrm{~K}$ as compared to a loss of $1.2 \pm 0.3 \mathrm{ppmv}$ at $460 \mathrm{~K}$ computed from the original Match technique. Our ozone loss rates agree very well with numerous other papers on AASE-2/EASOE including both in situ observations and photochemical model studies. Discrepancies in ozone loss rates between Match and our PV/Theta calculations lie in part in the fact that the PV/Theta approach only analyzes ozonesondes in the core of the vortex, completely neglecting the ozonesonde observations in the edge region where much of the loss may have occurred in 1992.

We suggest an alternative approach to Match based on trajectory mapping. TM Match requires no filtering of the data and relies upon the large number of matches that can be obtained to compensate for the increased uncertainties associated with the individual matches. The approach weights the ozone loss rates implicitly by including an estimate of the likelihood of a match in the calculation. Furthermore, when determining the loss rates from the ozone change and sunlight data, we use a two-parameter (slope and intercept) fit rather than the one-parameter (slope) fit that was used in the original Match technique and our version of Match. Our study indicates that while this approach is statistically more defensible, the loss rates so calculated are smaller in magnitude than those found using the original Match technique and numerous other estimates of ozone loss in 2000, calling into question the use of a trajectory approach in ozone loss rate calculations.

One possible explanation for the difference between the trajectory mapping and original Match results is that the latter may unintentionally select highly localized episodes of large ozone losses. TM Match includes far more matches and, therefore, the effect of isolated events of apparently large amounts of ozone loss is mitigated. The largest ozone loss rate of the original Match technique may not be representative of conditions throughout the entire vortex simultaneously, but rather in specific locations in the vortex, as suggested by Salawitch et al. (1993) for ER-2 data during AASE-2/EASOE.

Overall, the generally larger magnitude of the ozone loss rates found in the original Match as compared to our version 
of Match and the TM Match results may be due to the higher descent rates associated with the ECMWF trajectories, as indicated by a diagnostic comparison of ECMWF and UKMO trajectories in January 1992. Given the large vertical gradient at the altitudes of the Match analyses (450-500 K), such differences in descent can result in large differences in the calculated ozone loss, with dynamic changes being aliased into chemical loss rate calculations. For future Match studies, our results suggest that the meteorological field used in the trajectory calculations is an important factor in the calculated ozone loss rates. The variability in descent further suggests an additional uncertainty be attached to these ozone loss rates to account for this sensitivity.

In conclusion, we believe that ozone loss rates calculated via the original Match technique for January should be associated with larger uncertainties than the statistical error bars that have been previously published and which we have successfully duplicated in this study. While large loss rates may exist somewhere within the polar vortex region, they likely are not representative of conditions throughout the vortex. Furthermore, the large ozone loss rates from Match remain troublingly inconsistent with our current understanding of polar stratospheric chemistry (e.g., Becker et al., 2000), while the smaller ozone loss rates found in our version of Match are more consistent with the currently accepted polar stratospheric chemistry. Although the Match studies have produced an appealing and consistent picture of high ozone loss rates associated with large areas of cold temperatures (areas that often foster the development of PSCs), the picture may not be so clear when the all of the errors are taken into consideration appropriately. While Match represents a powerful approach to studying ozone loss, it must be applied with great care in order to produce reliable, robust results.

Acknowledgements. An enormous debt of gratitude is owed M. Rex, whose collaboration, contributions, advice, and review of a preliminary copy of this manuscript have been invaluable. Many thanks also to R. Stolarski, with whom the first author held countless hours of conversation about the topics covered in this paper and without whose input this paper might never have come to fruition. Also, special thanks to the teams at the various ozonesonde stations throughout the Northern Hemisphere for their hard work in launching sondes as part of the Match campaigns. NASA's EOS Interdisciplinary Science Program funds this research. We would like to thank the reviewers for their helpful comments for improving our manuscript.

Edited by: W. T. Sturges

\section{References}

Becker, G., Muller, R., McKenna, D. S., Rex, M., and Carslaw, K. S.: Ozone loss rates in the Arctic stratosphere in the winter 1991/92: Model calculations compared with Match results, Geophys. Res. Lett., 25, 4325-4328, 2000.

Becker, G., Muller, R., McKenna, D. S., Rex, M., Carslaw, K. S., and Oelhaf, H.: Ozone loss rates in the Arctic stratosphere in the winter 1994/1995: Model simulations underestimate results of the Match analysis, J. Geophys. Res., 105, 15 175-15 184, 2000.

Bojkov, B. R. and Bojkov, R. D.: Vertical Ozone Distribution over the European Polar Sector, Air Pollution Report 66: Proceedings of the fourth European workshop on Polar Stratospheric Ozone, Schliersee, Germany, 181-184, 23-27 September 1997.

Braathen, G. O., Rummukainen, M., Kyrö, E., et al.: Temporal development of ozone within the arctic vortex during the winter of 1991/92, Geophys. Res. Lett., 21, 1407-1410, 1994.

Browell, E. V., Butler, C. F., Fenn, M. A., Grant, W. B., Ismail, S., Schoeberl, M. R., Toon, O. B., Loewenstein, M., and Podolske, J. R.: Ozone and aerosol changes during the 1991-1992 Airborne Arctic Stratospheric Expedition, Science, 261, 1155-1158, 1993.

Chipperfield, M. P.: Multiannual simulations with a threedimensional chemical transport model, J. Geophys. Res., 104, 1781-1806, 1999.

Danilin, M. Y., Santee, M. L., Rodriguez, J. M., Ko, M. K. W., Mergenthaler, J. M., Kumer, J. B., Tabazadeh, A., and Livesey, N. J.: Trajectory hunting: A case study of rapid chlorine activation in December 1992 as seen by UARS, J. Geophys. Res., 105, 4003-4018, 2000.

Dickinson, R. E.: A method of parameterization for infrared cooling between altitudes of 30 to $70 \mathrm{~km}$, J. Geophys. Res., 78, 44514457, 1973.

Douglass, A. R., Rood, R. B., Stolarski, R. S., et al.: Global 3dimensional constituent fields derived from profile data, Geophys. Res. Lett., 17, 525-528, 1990.

Dunkerton, T. J. and Delisi, D. P.: Evolution of potential vorticity in the winter stratosphere of January-February 1979, J. Geophys. Res., 91, 1199-1208, 1986.

Efron, B.: The jackknife, the bootstrap, and other resampling plans, SIAM, Philadelphia, PA, 1982.

Geleyn, J. F. and Hollingsworth, A.: An economical analyitical method for the computation of the interaction between scattering and line absorption of radiation, Beitr. Phys. Atmos., 52, 1-16, 1979.

Grooß, J.-U. and Müller, R.: The impact of mid-latitude intrusions into the polar vortex on ozone loss estimates, Atmos. Chem. Phys., 3, 395-402, 2003,

SRef-ID: 1680-7324/acp/2003-3-395.

Kerr, J. B., Fast, H., McElroy, C. T., Oltmans, S. J., Lathrop, J. A., Kyrö, E., Paukkunen, A., Claude, H., Köhler, U., Sreedharan, C. R., Takao, T., and Tsukagoshi, Y.: The 1991 WMO International Ozonesonde Intercomparison at Vanscoy, Canada, Atmos. Ocean, 32 (4), 685-716, 1994.

Klein, U., Wholtmann, I., Lindner, K., and Künzi, K. F., Ozone depletion and chlorine activation in the Arctic polar vortex during the winters of 1994/95 and 1995/96, J. Atmos. Chem., 39, 123138, 2001.

Komhyr, W. D.: Electrochemical concentration cells for gas analysis, Ann. Geophys., 25, 203-210, 1969. 
Komhyr, W. D.: Operations Handbook: Ozone measurements to $40 \mathrm{~km}$ altitude with mode $4 \mathrm{~A}$ electrochemical concentration cell (ECC) ozonesondes (used with 1680-Mhz radiosondes), NOAA Technical Memorandum ERLARL-149, 1986.

Komhyr, W. D. and Harris, T. B.: Development of an ECC ozonesonde, NOAA Technical Report ERI, 200-APCL 18, 1971.

Komhyr, W. D., Barnes, R. A., Brothers, G. B., Lathrop, J. A., and Opperman, D. P.: Electrochemical concentration cell performance evaluation during STOIC, J. Geophys. Res., 100, 92319244, 1995

Lacis, A. A. and Hansen, J. E.: A parameterization for the absorption of solar radiation in the earth's atmosphere, J. Atmos. Sci., 31, 118-133, 1974.

Lait, L. R.: An Alternative form of potential vorticity, J. Atmos. Sci., 51, 12, 1754-1759, 1994.

Lait, L. R., Schoeberl, M. R., Newman, P. A., et al.: Ozone loss from quasi-conservative coordinate mapping during the 19992000 SOLVE/THESEO 20002000 campaigns, J. Geophys. Res., 107, 8274, doi:10.1029/2001JD000998, 2002.

Lait, L. R., Schoberl, M. R., Newman, P. A., et al.: Reconstruction of O-3 and N2O fields from ER-2, DC-8, and balloon observations, Geophys. Res. Lett., 17, 521-524, 1990.

Lucic, D., Harris, N. R. P., Pyle, J. A., and Jones, R. L.: A technique for estimating polar ozone loss: Results for the northern 1991/92 winter using EASOE data, J. Atmos. Chem., 34, 365-383, 1999.

Manney, G. L., Froidevaux, L., Waters, J., et al.: Chemical depletion of ozone in the Arctic lower stratosphere during winter 1992-93, Nature, 370, 429-434, 1994.

Manney, G. L., Michelsen, H. A., Santee, M. L., Gunson, M. R., Irion, F. W., Roche, A. E., and Livesey, N. J.: Polar vortex dynamics during spring and fall diagnosed using trace gas observations from the Atmospheric Trace Molecule Spectroscopy instrument, J. Geophys. Res., 104, 18 841-18 866, 1999.

McIntyre, M. E.: Towards a Lagrangian-mean description of stratospheric circulations and chemical transports, Philos. T. Roy. Soc. A., 296, 129-148, 1980.

Morris, G. A., Schoeberl, M. R., Sparling, L. C., et al.: Trajectory mapping and applications to data from the Upper Atmosphere Research Satellite, J. Geophys. Res., 100, 16 491-16 505, 1995.

Morris, G. A., Gleason, J. F., Ziemke, J., and Schoeberl, M. R.: Trajectory mapping: A tool for validation of trace gas observations, J. Geophys. Res., 105, 17 875-17 894, 2000.

Nash, E. R., Newman, P. A., Rosenfield, J. E., and Schoeberl, M. R.: An objective determination of the polar vortex using Ertel's potential vorticity, J. Geophys. Res., 101, 9471-9478, 1996.

Newman, P. A., Harris, N. R. P., Adriani, A., et al.: An overview of the SOLVE/THESEO 20002000 campaign, J. Geophys. Res., 107, doi:10.1029/2001JD001303, 2002.

Peterson, R. A. and Uccellini, L. W.: The computation of isentropic atmospheric trajectories using a "Discrete Model" formulation, Mon. Wea., Rev., 107, 566-574, 1979.

Pierce, R. B., Grose, W. L., and Russell, III, J. R.: Evolution of Southern Hemisphere air masses observed by HALOE, Geophys. Res. Lett., 21, 213-216, 1994.

Plumb, R. A., Waugh, D. W., and Chipperfield, M. P.: The effects of mixing on tracer relationships in the polar vorticies, J. Geophys. Res., 105, 10 047-10 062, 2000.

Plumb, R. A., Waugh, D. W., Atkinson, R. J., Newman, P. A., Lait, L. R., Schoeberl, M. R., Browell, E. V., Simmons, A. J., and
Lowenstein, M.: Intrusions into the lower stratospheric Arctic vortex during the winter of 1991/1992, J. Geophys. Res., 99, 1089-1106, 1994.

Plumb, R. A., Ko, M. K. W., and Shia, R. L.: Representation of localized aircraft NOy emissions in a 2-dimensional model of stratospheric ozone, J. Geophys. Res., 100, 20 901-20 911, 1995.

Podolske, J. R., Loewenstein, M., Weaver, A., Strahan, S. E., and Chan, K. R.: Northern-Hemisphere nitrous-oxide morphology during the 1989 AASE and the 1991-1992 AASE-II campaigns, Geophys. Res. Lett., 20, 2535-2538, 1993.

Profitt, M. H., Aikin, K., Margitan, J. J., Loewenstein, M., Podolske, J. R., Weaver, A., Chan, K. R., Fast, H., and Elkins, J. W.: Ozone loss inside the northern polar vortex during the 1991-1992 winter, Science, 261, 1150-1154, 1993.

Randall, C.E., Lumpe, J. D., Bevilacqua, R. M., et al.: Reconstruction of three-dimensional ozone fields using POAM III during SOLVE, J. Geophys. Res., 107, 8299, doi:10.1029/2001JD000471, 2002.

Redaelli, G., Lait, L. R., Schoeberl, M. R., et al.: UARS MLS O3 soundings compard with lidar measurements using the conservative coordinates reconstruction technique, Geophys. Res. Lett., 21, 1535-1538, 1994.

Rex, M.: Stratospharische Ozonabbauraten aus den Ozonsondendaten der EASOE-Kampagne, Masters thesis, Georg August University, Göttingen, Germany, 1993.

Rex, M., Harris, N. R. P., von der Gathen, P., et al.: Prolonged stratospheric ozone loss in the 1995-96 Artic winter, Nature, 389, 835-838, 1997.

Rex, M., von der Gathen, P., Harris, N. R. P., et al.: In situ measurements of stratospheric ozone depletion rates in the Arctic winter 1991/1992: A Lagrangian approach, J. Geophys. Res., 103, 5843-5853, 1998.

Rex, M., von der Gathen, P., Braathen, G.O., et al.: Chemical ozone loss in the Arctic winter 1994/95 as determined by the MATCH technique, J. Atmos. Chem., 32, 35-59, 1999.

Rex, M., Salawitch, R. J., Harris, N. R. P., et al.: Chemical depletion of Arctic ozone in winter 1999/2000, J. Geophys.Res., 107(D20), 8276, doi:10.1029/2001JD000533, 2002.

Rex, M., Salawitch, R. J., Santee, M. L., Waters, J. W., Hoppel, $\mathrm{K}$. and Bevilacqua, R.: On the unexplained stratospheric ozone losses during cold Arctic Januaries, Geophys. Res. Lett., 30, 1008, doi:10.1029/2002GL016008, 2003.

Richard, E. C., Aikin, K. C., Andrews, A. E., et al.: Severe chemical ozone loss inside the Arctic polar vortex during winter 19992000 inferred from in situ airborne measurements, Geophys. Res. Lett., 28, 2197-2200, 2001.

Rosenfield, J. E., Newman, P. A., and Schoeberl, M. R.: Computations of Diabatic Descent in the Stratospheric Polar Vortex, J. Geophys. Res., 99, 16677-16 689, 1994.

Salawitch, R. J., Wofsy, S. C., Gottlieb, E. W., et al.: Chemical loss of ozone in the arctic polar vortex in the winter of 1991-1992, Science, 261, 1146-1149, 1993.

Salawitch, R. J., McElroy, M. B., Yatteau, J. H., et al.: Loss of ozone in the arctic vortex for the winter of 1989, Geophys. Res. Lett., 17, 561-564, 1990.

Sander, S. P., Friedl, R. R., Ravishankara, A. R., et al.: Chemical Kinetics and Photochemical Data for Use in Atmospheric Studies: Evaluation Number 14, JPL Publ. 02-25, 2003. 
Santee, M. L., Manney, G. L., Livesey, N. J., and Waters, J. W.: UARS Microwave Limb Sounder observations of denitrification and ozone loss in the 2000 Arctic late winter, Geophys. Res. Lett., 27, 3213-3216, 2000.

Schoeberl, M. R. and Hartmann, D. L.: The dynamics of the stratospheric polar vortex and its relation to springtime ozone depletions, Science, 251, 46-52, 1991.

Schoeberl, M. R. and Lait, L. R.: Conservative-coordinate transformations for atmospheric measurements, in Proceedings of the International School of Physics: The Use of EOS for Studies of Atmospheric Physics, Elsevier Science, New York, 1992.

Schoeberl, M. R. and Sparling, L.: Trajectory Modeling, in: Diagnostic Tools in Atmospheric Physics, edited by: Fiocco, G. and Visconti, G., Proceedings of the International School of Physics "Enrico Fermi", 124, 289-306, 1995.

Schoeberl, M. R., Lait, L. R., Newman, P. A., et al.: Reconstruction of the constituent distribution and trends in the Antarctic polar vortex from ER-2 flight observations, J. Geophys. Res., 94, 16815-16845, 1989.

Schoeberl, M. R., Newman, P. A., Lait, L. R., et al.: An assessment of ozone loss during the 1999-2000 SOLVE/THESEO 2000 Arctic campaign, J. Geophys. Res., 107(D20), 8261, doi:10.1029/2001JD000412, 2002.

Schulz, A., Rex, M., Steger, J., et al.: Match observations in the Arctic winter 1996/97: High stratospheric ozone loss rates correlate with low temperatures deep inside the polar vortex, Geophys. Res. Lett., 27, 205-208, 2000.

Schulz, A., Rex, M., Harris, N. R. P., et al.: Arctic ozone loss in threshold conditions: Match observations in1997/1998 and 1998/1999, J. Geophys. Res., 106, 7495-7503, 2001.

Sinnhuber, B. M., Chipperfield, M. P., Davies, S., Burrows, J. P., Eichmann, K. U., Weber, M., von der Gathen, P., Guirlet, M., Cahill, G. A., Lee, A. M., and Pyle, J. A.: Large loss of total ozone during the Arctic winter of 1999/2000, Geophys. Res. Lett., 27, 3473-3476, 2000.
Solomon, S.: Stratospheric ozone depletion: A review of concepts and history, Rev. Geophys., 37, 275-316, 1999.

Strahan, S. E.: Climateologies of lower stratospheric $\mathrm{NO}_{\mathrm{y}}$ and $\mathrm{O}_{3}$ and correlationswith $\mathrm{N}_{2} \mathrm{O}$ based on in situ observations, J. Geophys. Res., 104, 30 463-30 480, 1999a.

Strahan, S. E., Loewenstein, M., and Podolske, J. R.: Climatology and small-scale structure of lower stratospheric $\mathrm{N}_{2} \mathrm{O}$ based on in situ observations, J. Geophys. Res., 104, 2195-2208, 1999 b.

Swinbank, R. and O'Neill, A.: A stratosphere-troposphere data assimilation system, Mon. Wea. Rev., 122, 686-702, 1994.

Tilmes, S., Müller, R., Grooß, J.-U., McKenna, D. S., Russell, J. M., and Sasano, Y.: Calculation of chemical ozone loss in the Arctic winter 1996-1997 using ozone-tracer correlations: Comparison of Improved Limb Atmospheric Spectrometer (ILAS) and Halogen Occultation Experiment (HALOE) results, J. Geophys. Res., 108, 4045, doi:10.1029/2002JD002213, 2003.

Tilmes, S., Müller, R., Grooß, J.-U., and Russell, J. M.: Ozone loss and chlorine activation in the Arctic winters 1991-2003 derived with the TRAC method, Atmos. Chem. Phys, 4, 2181-2213, 2004,

\section{SRef-ID: 1680-7324/acp/2004-4-2181.}

von der Gathen, P., Rex, M., Harris, N. R. P., et al.: Observational evidence for chemical ozone depletion over the Arctic in winter 1991-92, Nature, 375, 131-134, 1995.

Waugh, D. W. and Plumb, R. A.: Contour advection with surgery - a technique for investigating finescale structure in tracer transport, J. Atmos. Sci., 51, 530-540, 1994.

Waugh, D. W., Plumb, R. A., Atkinson, R. J., Schoeberl, M. R., Lait, L. R., Newman, P. A., Lowenstein, M., Toohey, D. W., and Webster, C. R.: Transport of material out of the stratospheric Arctic vortex by Rossby wave breaking, J. Geophys. Res., 99, 1071-1088, 1994. 